\title{
Loop Heat Pipe Operation Using Heat Source Temperature for Set Point Control
}

\author{
Jentung Ku \\ NASA Goddard Space Flight Center \\ Greenbelt, Maryland \\ 301-286-3130 \\ Jentung.Ku-1@nasa.gov \\ Kleber Paiva, Marcia Mantelli \\ Federal University of Santa Catarina \\ Florianópolis, Santa Catarina, Brazil \\ 2011 Spacecraft Thermal Control Workshop \\ El Segundo, California, March 8-10, 2011
}




\section{Introduction}

- Loop heat pipes (LHPs) have been used for thermal control of several NASA and commercial orbiting spacecraft.

- The LHP operating temperature is governed by the saturation temperature of its compensation chamber (CC).

- Most LHPs use the CC temperature for feedback control of its operating temperature.

- There exists a thermal resistance between the heat source to be cooled by the LHP and the LHP's CC. Even if the CC set point temperature is controlled precisely, the heat source temperature will still vary with its heat output.

- For most applications, controlling the heat source temperature is of most interest.

- A logical question to ask is: "Can the heat source temperature be used for feedback control of the LHP operation?"

- A test program has been implemented to answer the above question. 


\section{Test Program}

- Objective

- To investigate the LHP performance using the CC temperature and the heat source temperature for feedback control

- Test article

- A miniature LHP built by Thermacore in 2003 under NASA's Cross Enterprise Technology Development Program (CETDP)

- An aluminum thermal mass is attached to the LHP evaporator to serve as the instrument simulator.

- Test variables

- Location of the temperature sensor used for feedback control of LHP operation: CC, evaporator, and thermal mass

- Heat load to the thermal mass: 10W to $140 \mathrm{~W}$

- Aluminum thermal mass: $110 \mathrm{~g}$ and $350 \mathrm{~g}$

- Thermal control device attached to the CC: thermoelectric converter (TEC) and electric heater (EH)

- Temperature control scheme: PID (proportional-integral-derivative control) and on/off

- Only the results of PID control are presented. 


\section{CETDP MLHP Design}

- CETDP MLHP built by Thermacore - 2003

\begin{tabular}{|c|c|}
\hline Item & Description \\
\hline \multirow{2}{*}{ Evaporator } & SS - $6.35 \mathrm{~mm}$ O.D. x $51 \mathrm{~mm}$ length \\
\hline & Aluminum Shell \\
\hline \multirow{3}{*}{ Primary Wick } & SS - $5.6 \mathrm{~mm}$ O.D. x $2.4 \mathrm{~mm}$ I.D \\
\hline & $1.2 \mu \mathrm{m}$ pore size \\
\hline & $1.0 \times 10^{-14} \mathrm{~m}^{2}$ \\
\hline Secondary Wick & SS - screen, $400 \times 400$ mesh \\
\hline $\begin{array}{l}\text { Compensation } \\
\text { Chamber }\end{array}$ & SS - $9.52 \mathrm{~mm}$ O.D. x $25.5 \mathrm{~mm}$ length \\
\hline Vapor Line & SS - $1.59 \mathrm{~mm}$ O.D. x $610 \mathrm{~mm}$ length \\
\hline Liquid Line & SS - $1.59 \mathrm{~mm}$ O.D. x $795 \mathrm{~mm}$ length \\
\hline Condenser & $\begin{array}{l}\text { SS tubing - } 2.39 \mathrm{~mm} \text { O.D. } \times 200 \mathrm{~mm} \text { length } \\
\text { Saddle: aluminum }\end{array}$ \\
\hline Working Fluid & Ammonia, $1.5 \mathrm{~g}$ \\
\hline Total Mass & $79 \mathrm{~g}$ \\
\hline
\end{tabular}
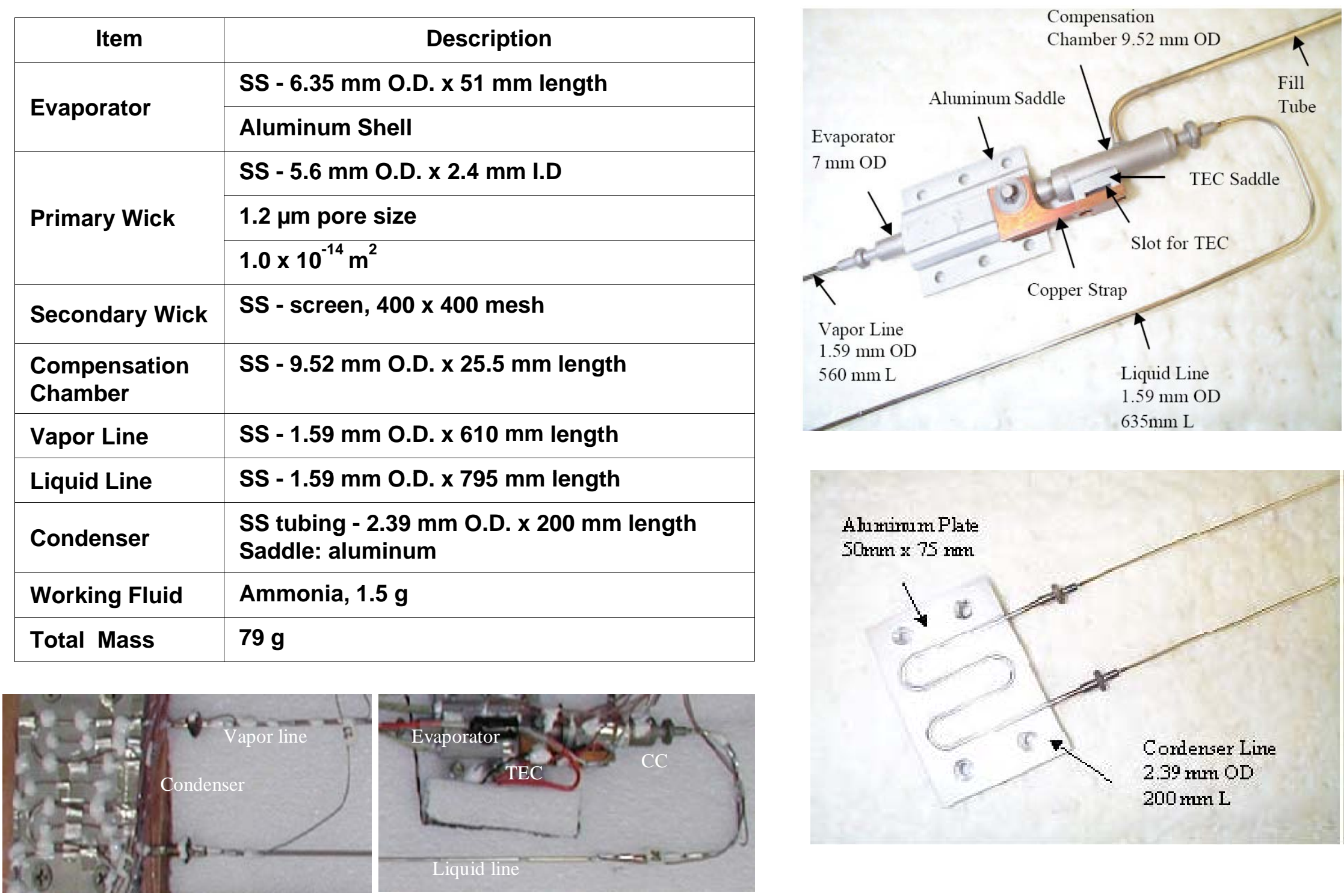


\section{TC Locations}

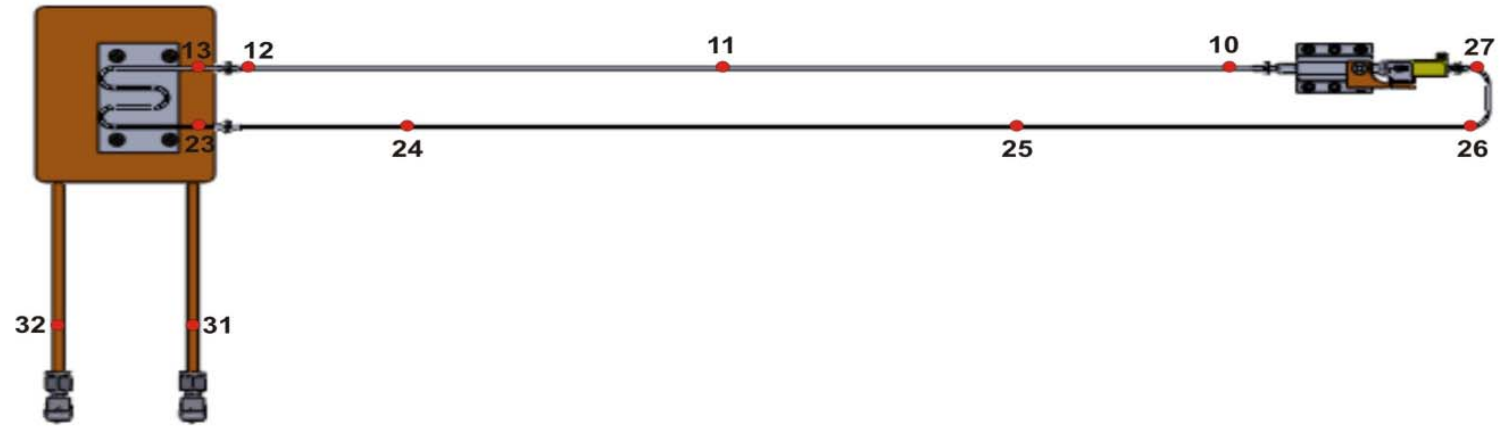

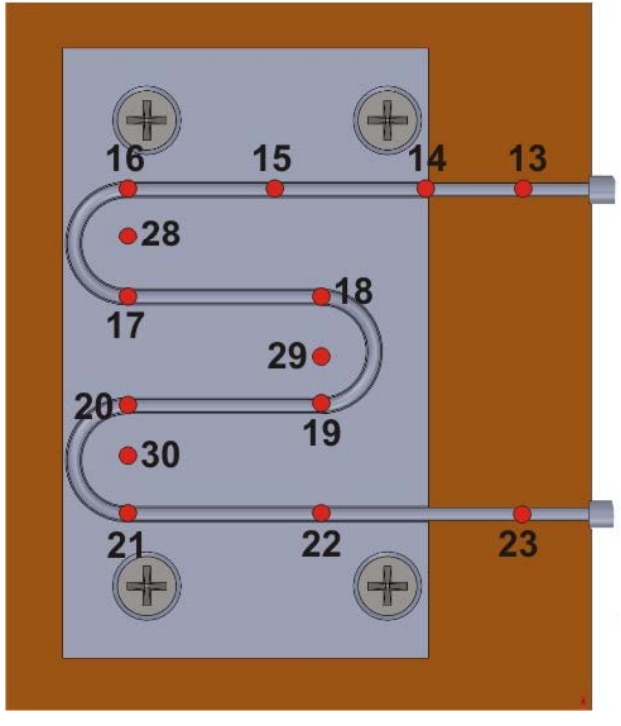

Condenser Section
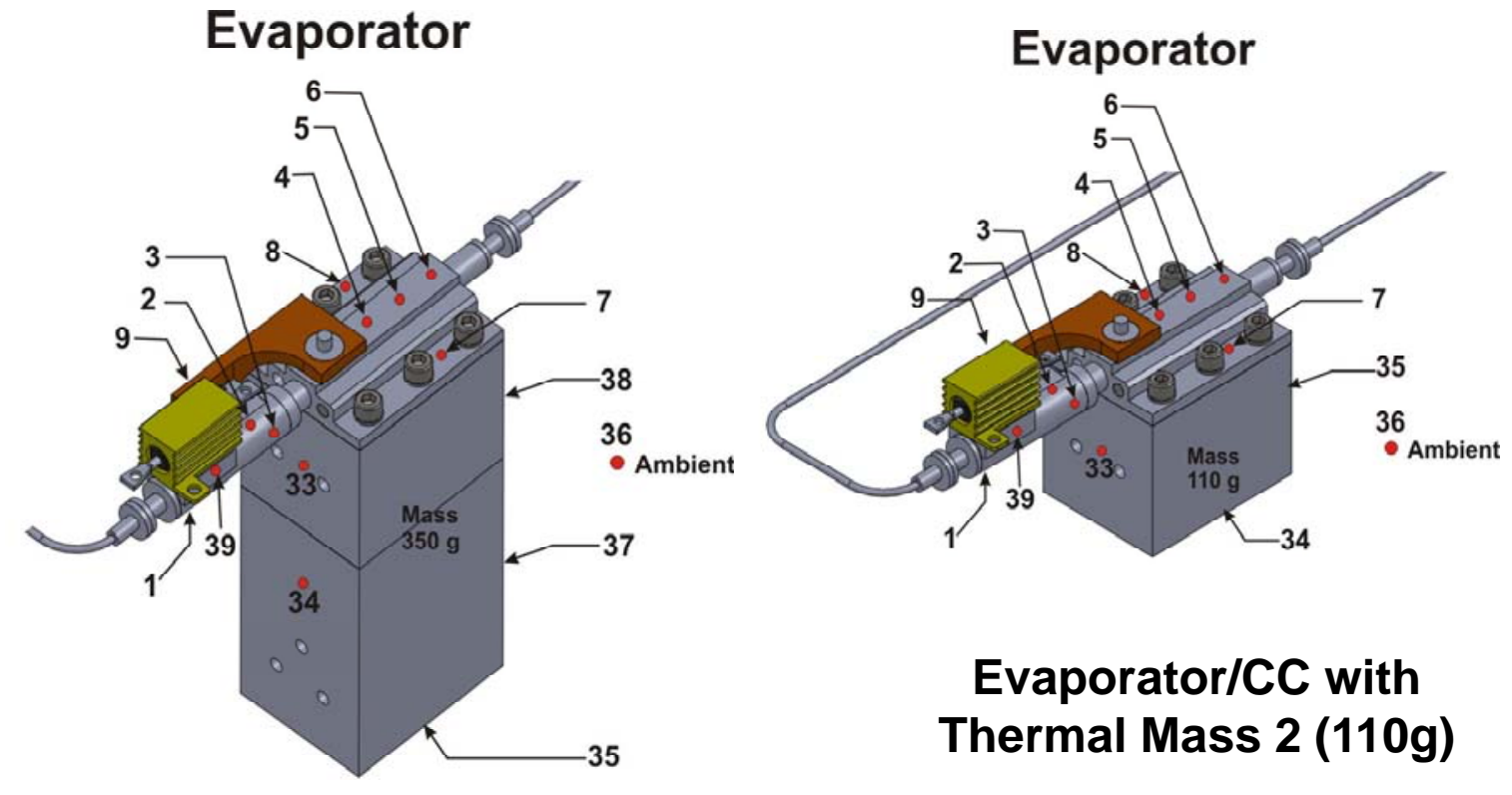

Evaporator/CC with Thermal Mass 1 (350g) 


\section{Location of Control Temperature Sensor}

- The location of the control temperature sensor for feedback control is shown below for conditions where $\mathbf{3 5 0}$ gram mass and 110 gram thermal mass were attached to the evaporator.

- TC\#2 on the CC

- TC\#5 on the evaporator

- TC\#33 on the thermal mass.

- Effect of high thermal resistance between thermal mass and LHP

- A large thermal resistance was imposed between the thermal mass and the evaporator in this test $(0.23 \mathrm{~K} / \mathrm{W}$ or $4.4 \mathrm{~W} / \mathrm{K})$.

- High thermal resistance: TC \#33 was used for feedback control

- Near-zero thermal resistance: TC\#5 was used for feedback control
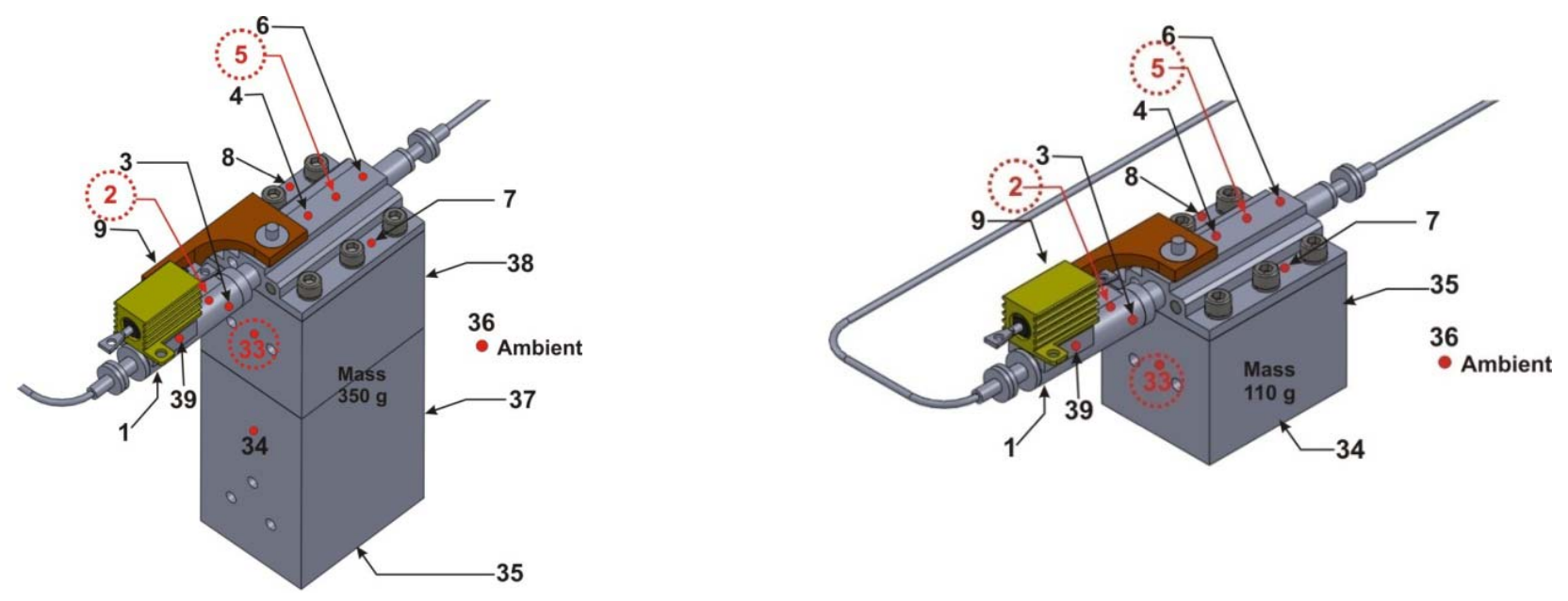


\section{Test Variables}

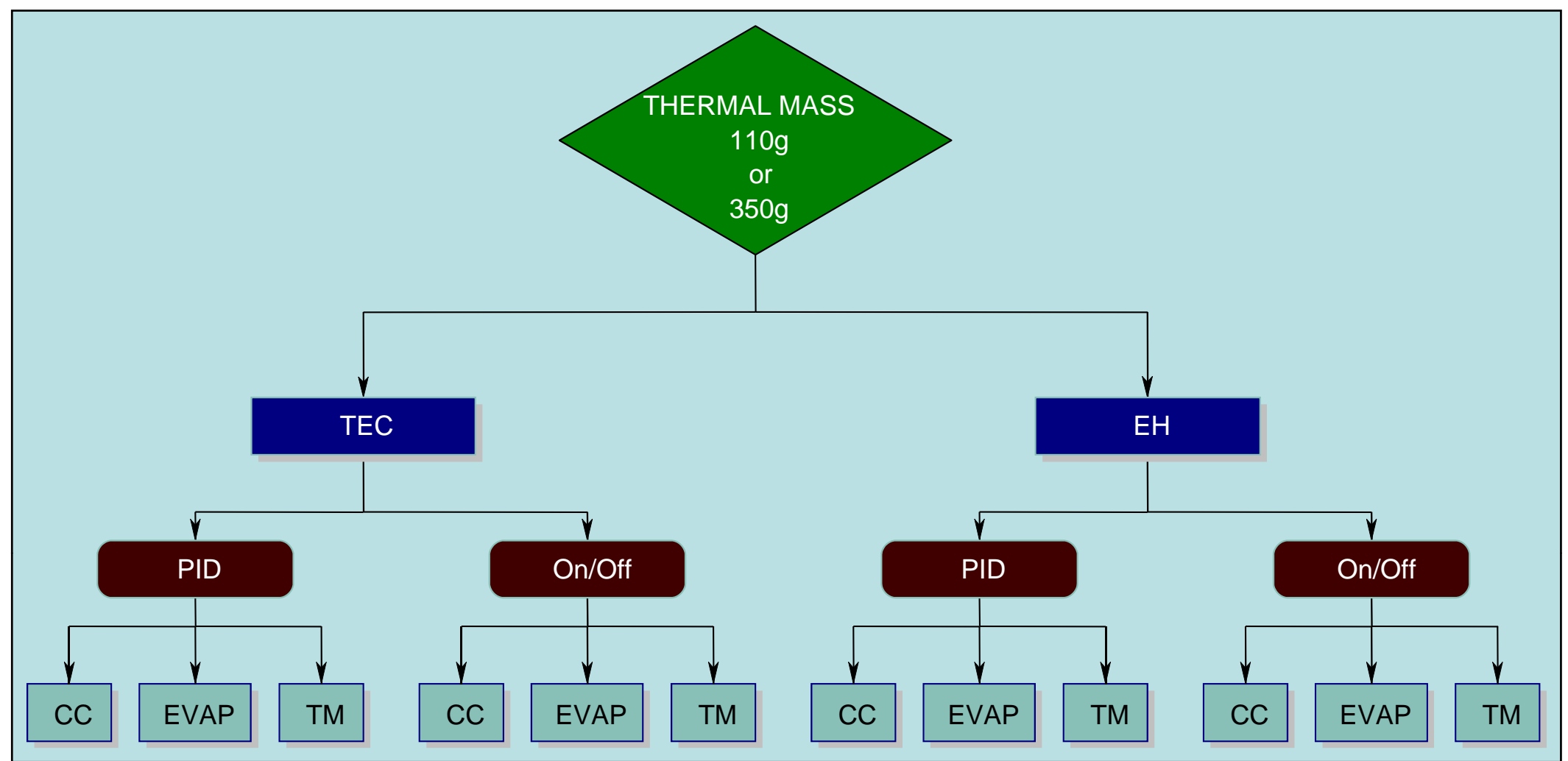




\section{EH versus TEC}

- The following charts show the effect of using LHP CC temperature and the heat source temperature for feedback control.

- The CC was not preheated prior to start-up.

- Also shown are the effect of using TEC and electrical heater for CC temperature control.

- All tests employed the PID control scheme.

- No sophisticated control algorithm was used for transient operation. 


\section{Controlled at 293K - EH/2W/PID/350g}

- CC, evaporator and TM temperatures were stable between $20 \mathrm{~W}$ and $120 \mathrm{~W}$.

- CC could no longer be controlled at $293 \mathrm{~K}$ at $140 \mathrm{~W}$ due to condenser limit (CC temperature rose to $297 \mathrm{~K}$ )

- The start-up transient is shown in next slide

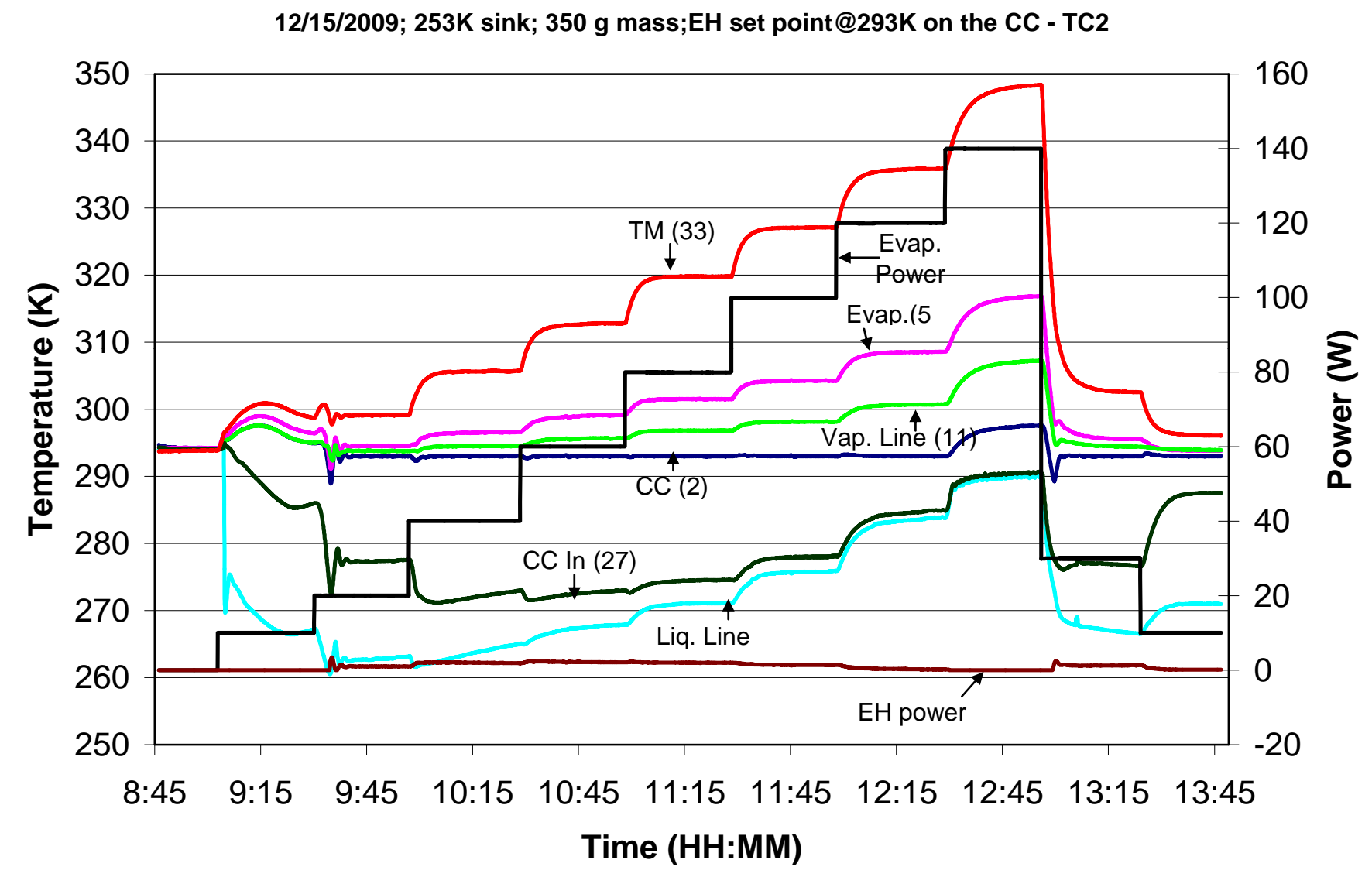




\section{Controlled at 293K - EH/2W/PID/350g}

- Loop started as soon the power was applied to TM.

- $\quad$ Right after start-up, CC temperature rose because of the return of warm liquid.

- The CC eventually reached its natural operating temperature of $295 \mathrm{~K}$, higher than desired set point.

- During the transient from $10 \mathrm{~W}$ to $20 \mathrm{~W}$, EH power (2W) was not enough to raise the CC temperature quickly.

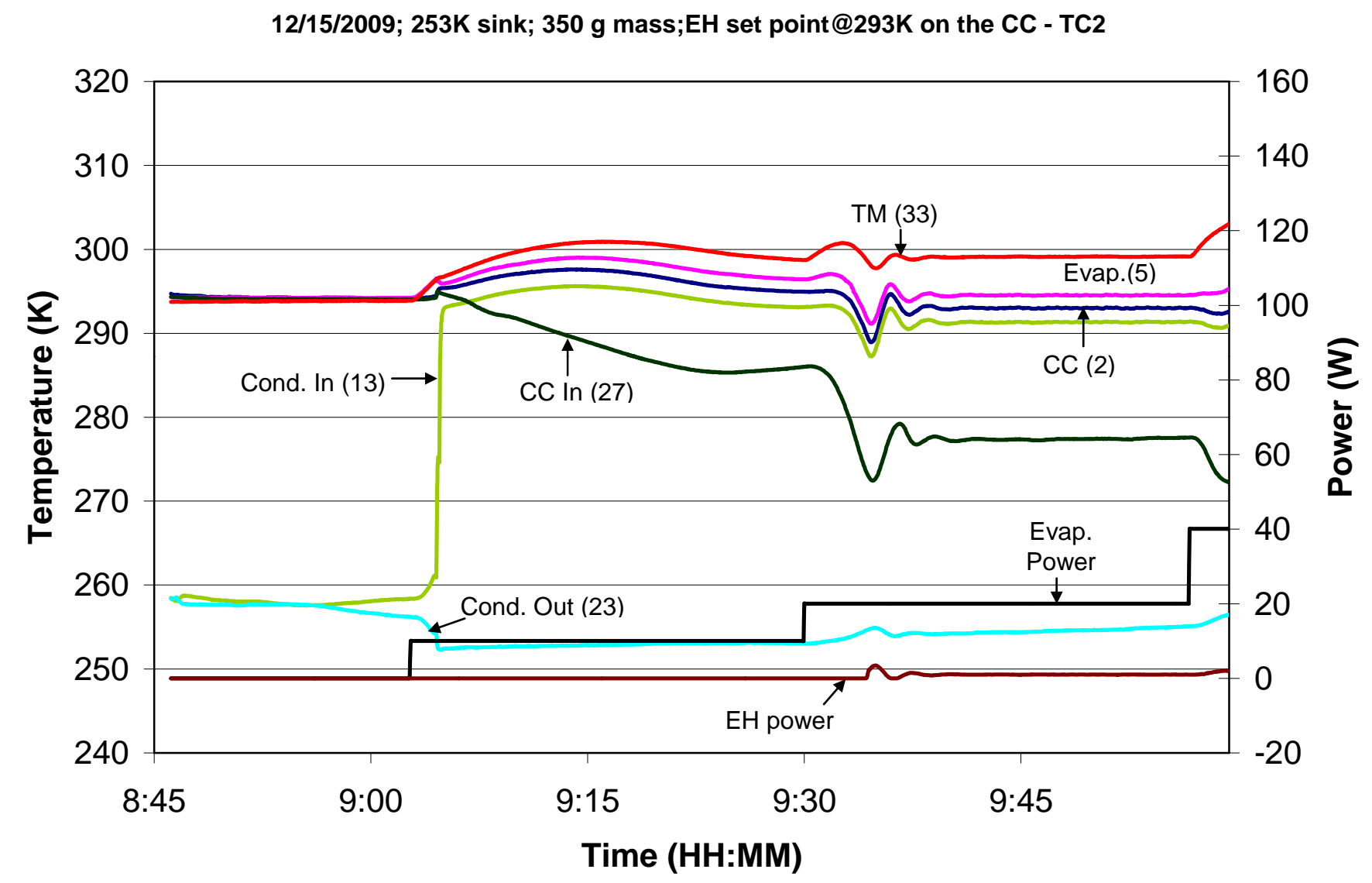




\section{Evaporator Controlled at 303K - EH/3W/PID/350g}

- $\quad$ Simulated near-zero thermal resistance between heat source and LHP.

- Evaporator temperature was stable at 303K between $10 \mathrm{~W}$ and $100 \mathrm{~W}$.

- The CC temperature decreased in steps between $20 \mathrm{~W}$ and $100 \mathrm{~W}$ in order to maintain evaporator at 303K.

- At 120W, the condenser limit was reached. The CC did not have enough subcooling to maintain the evaporator at 303K.

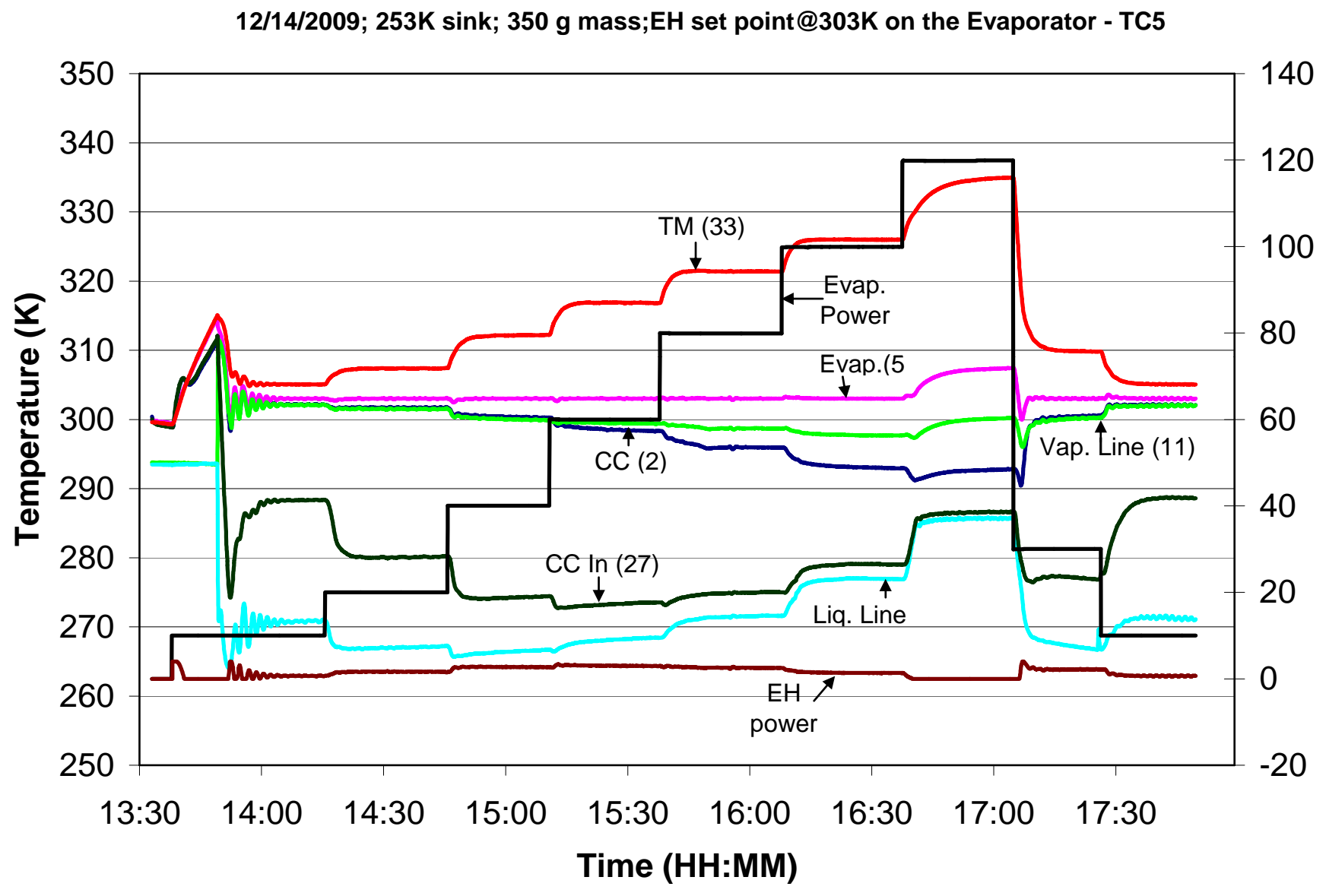




\section{Evaporator Controlled at 303K - EH/3W/PID/350g}

- Initially, CClevaporator at $299 \mathrm{~K}$. As $10 \mathrm{~W}$ was applied to evap, EH heated the CC because the evaporator set point was 303K.

- When the evaporator reached 303K, EH was deactivated. However, heat leak raised CC to 312K when the loop started with evaporator at 316K.

- $\quad$ Cold liquid led to CC temperature drop to $298 \mathrm{~K}$ and evaporator to $300 \mathrm{~K}$. EH heated the CC until evaporator reached 303K. This was followed by a few more cycles of temperature oscillation, and loop eventually reached SS. TM sensible heat also contributed to the temperature oscillations.

- The loop was never shut down (vapor line TC 11 was at CC saturation temperature all the time).

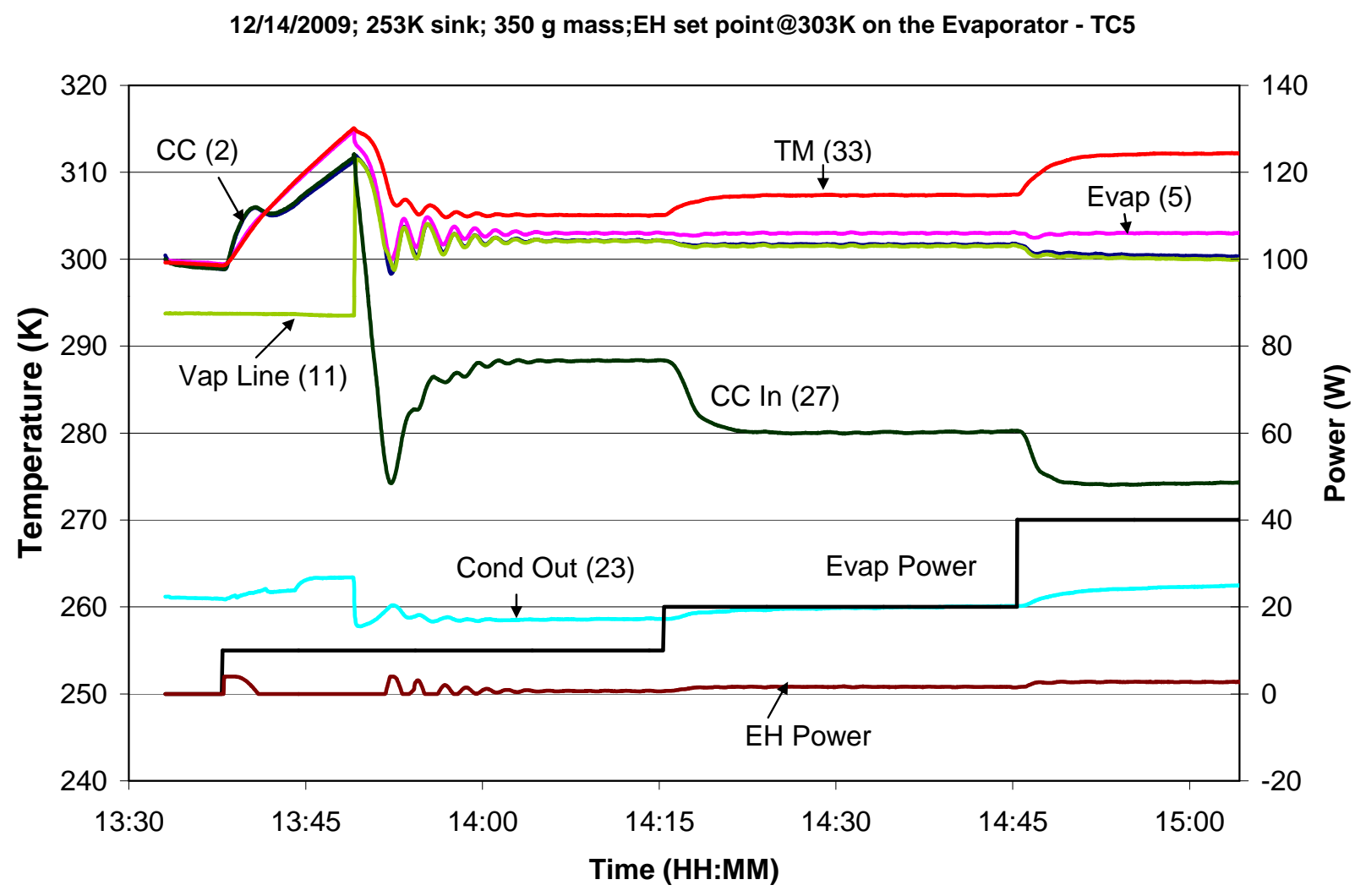




\section{TM Controlled at 313K - EH/4W/PID/350g}

- At $10 \mathrm{~W}$, the loop repeatedly started and shut down (see next slide).

- At $40 \mathrm{~W}, \mathrm{TM}$ oscillated between $312 \mathrm{~K}$ and $314 \mathrm{~K}$, less at $60 \mathrm{~W}$. No oscillation at $80 \mathrm{~W}$.

- At 100W, condenser limit and CC at 287K. 120W, condenser limit, CC at 292K.

- Temperature oscillations resumed at 30W and 10W (not just a start-up transient effect).

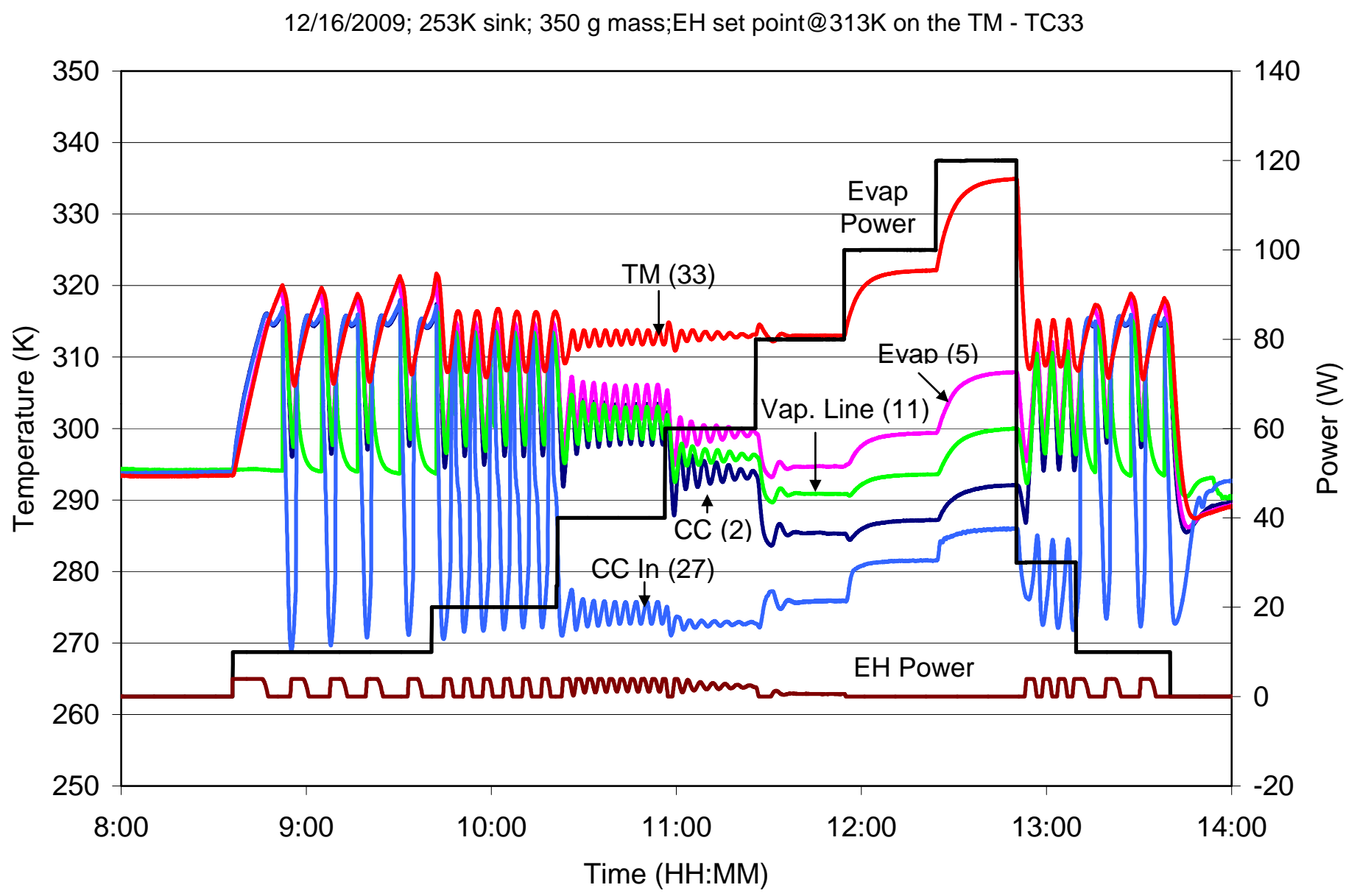




\section{TM Controlled at 313K - EH/4W/PID/350g}

- Initially, CC, evaporator, and TM were at 294K.

- When 10W was applied to evaporator, EH was on to heat the CC. When TM reached 313K, EH was deactivated. However, CC temperature rose due to heat leak from the evaporator.

- $\quad$ As the loop started, CC temperature dropped to $297 \mathrm{~K}$ due to cold liquid injection. TM was at $307 \mathrm{~K}$

- $\quad$ EH heated the CC. The loop was shut down with $4 \mathrm{~W}$ to $C C$ and $10 \mathrm{~W}$ to TM. The loop then repeated startup and shutdown.

- At 20W, the oscillation reduced. Loop did not completely shut down (TC 11 always followed TC 2) although forward/back flow alternated.

12/16/2009; 253K sink; 350 g mass;EH set point@313K on the TM - TC33

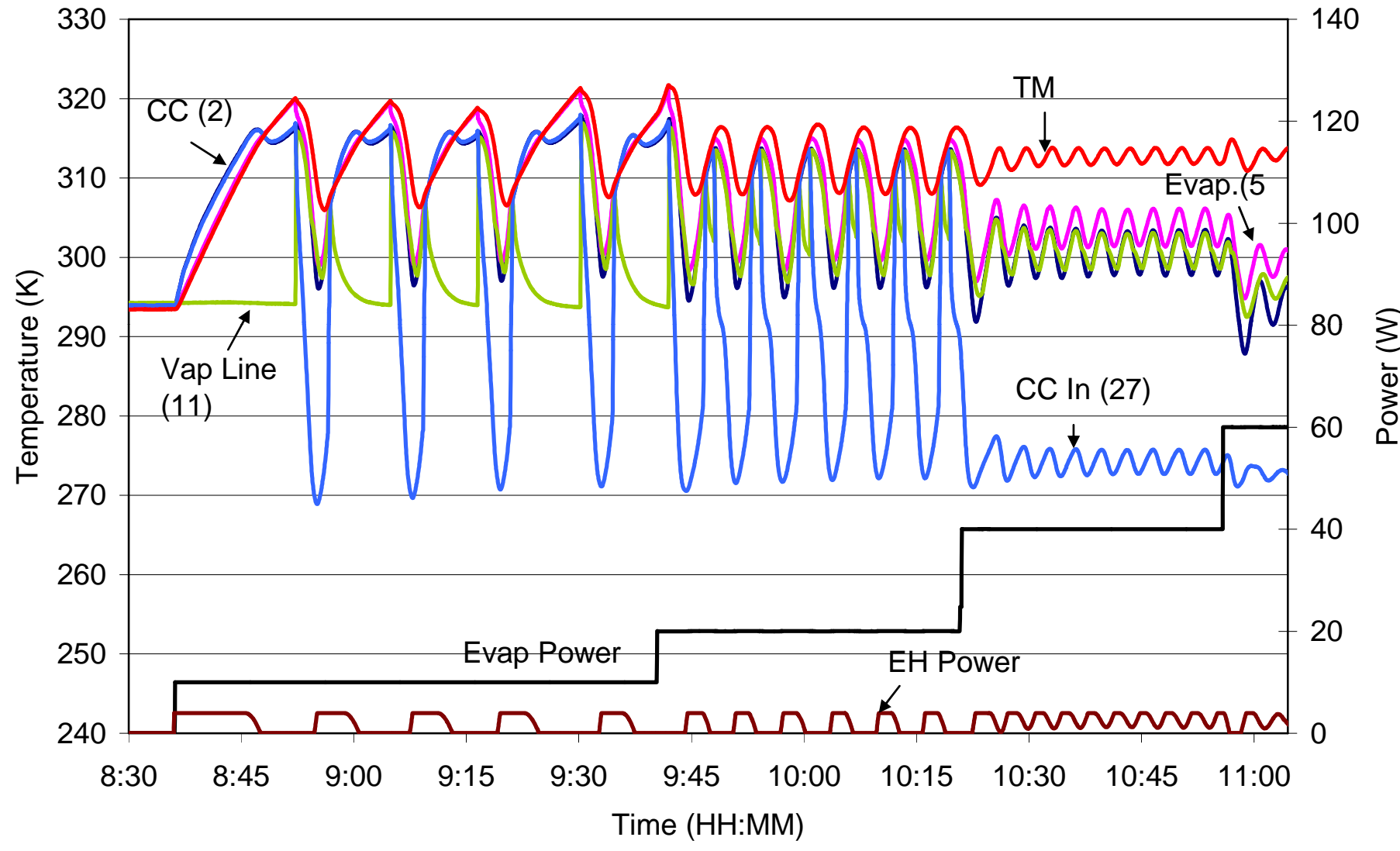




\section{Controlled at 293K - TEC/1W/PID/350g}

- CC, evaporator, and TM temperatures were stable between 10W and 120W. CC and TM temperatures increased with increasing power.

- $\quad$ CC temperature dropped when the heat load increased from $20 \mathrm{~W}$ to $40 \mathrm{~W}$ and from $40 \mathrm{~W}$ to $60 \mathrm{~W}$ because $1 \mathrm{~W}$ to TEC was not enough to heat the $\mathrm{CC}$ during the transient.

- At 140W, condenser limit was reached - TEC cooled the CC (negative TEC power).

- Performance was similar to that demonstrated in 2003 tests.

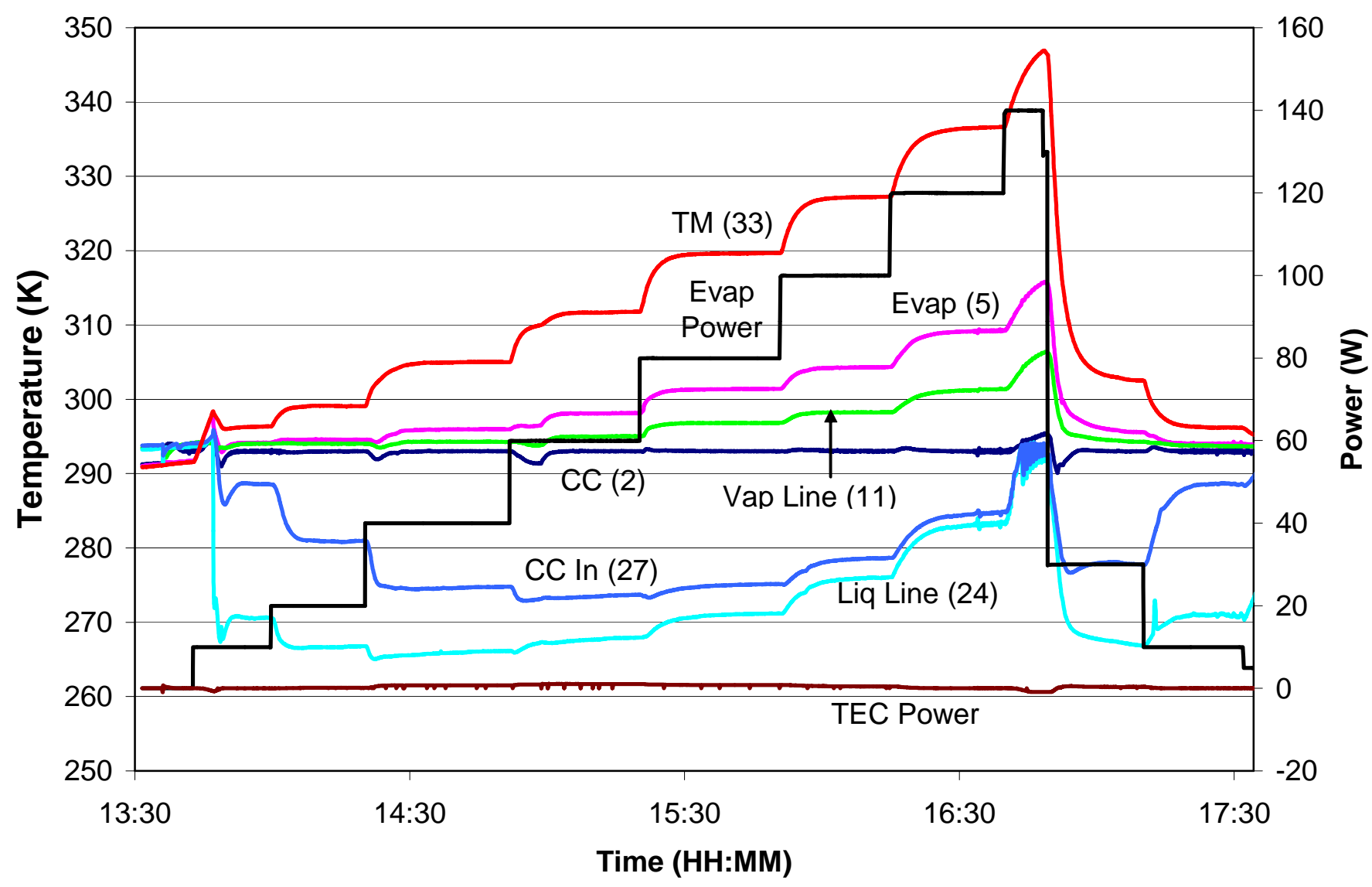




\section{Controlled at 293K - TEC/1W/PID/350g}

- When 10W was applied to TM, CC temperature rose due to heat leak. TEC cooled the CC.

- As the loop started, CC temperature dropped due to injection of cold liquid. TEC raised CC temperature.

- The TEC power of less than $1 \mathrm{~W}$ was not sufficient for $\mathrm{CC}$ temperature control during transients.

12/07/2009; 253K sink; 350 g mass;TEC set point@293K on the CC - TC2; PID

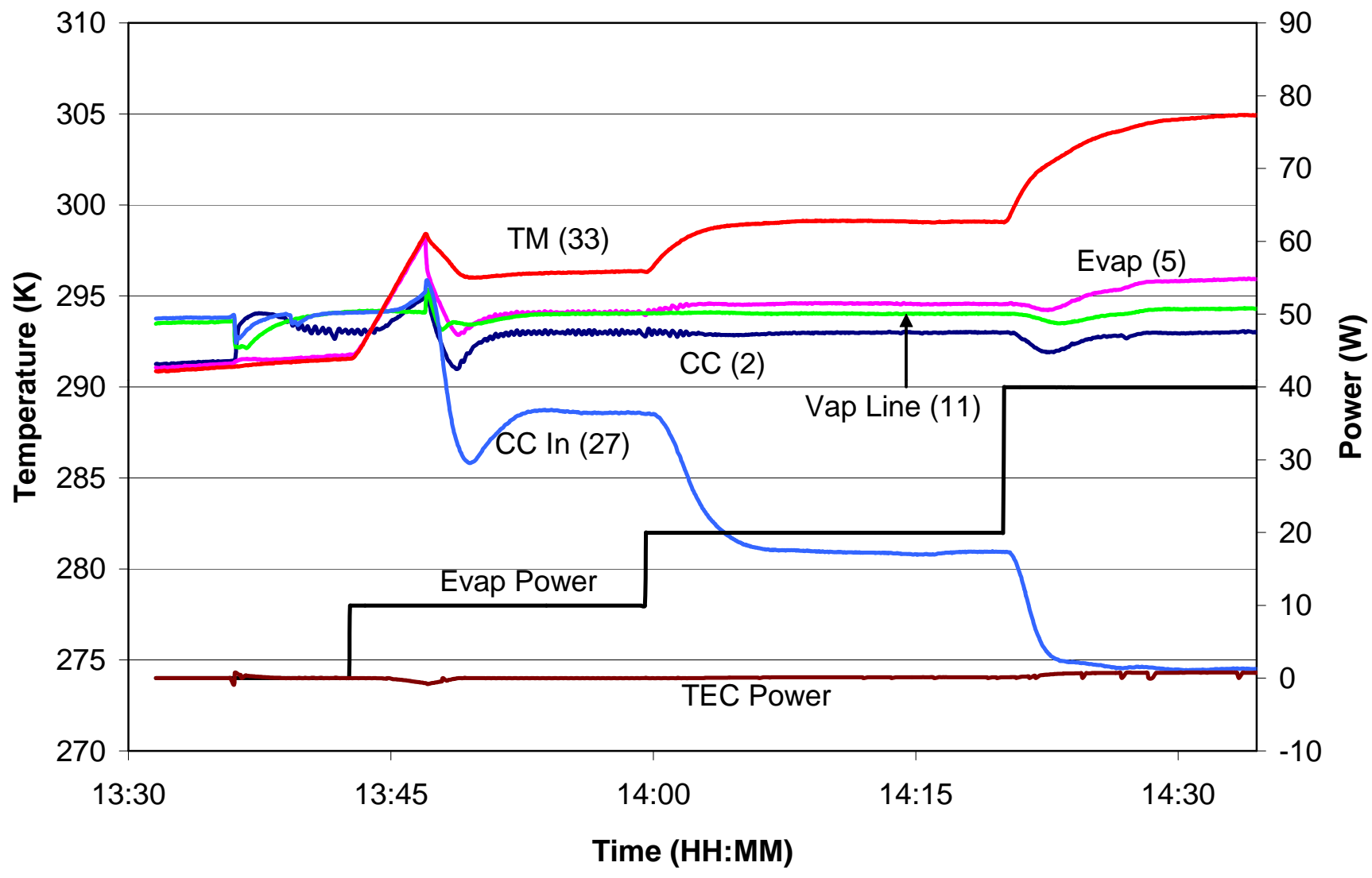




\section{Evaporator Controlled at 303K - TEC/1W/PID/350g}

- Evaporator at $303 \mathrm{~K}$ between $10 \mathrm{~W}$ and 100W. CC, evaporator and TM temperatures were stable.

- At $120 \mathrm{~W}$, condenser limit - evaporator was above 303K. TEC cooled CC.

- Evaporator was controlled at 303K again when the heat load decreased to $30 \mathrm{~W}$ and $10 \mathrm{~W}$.

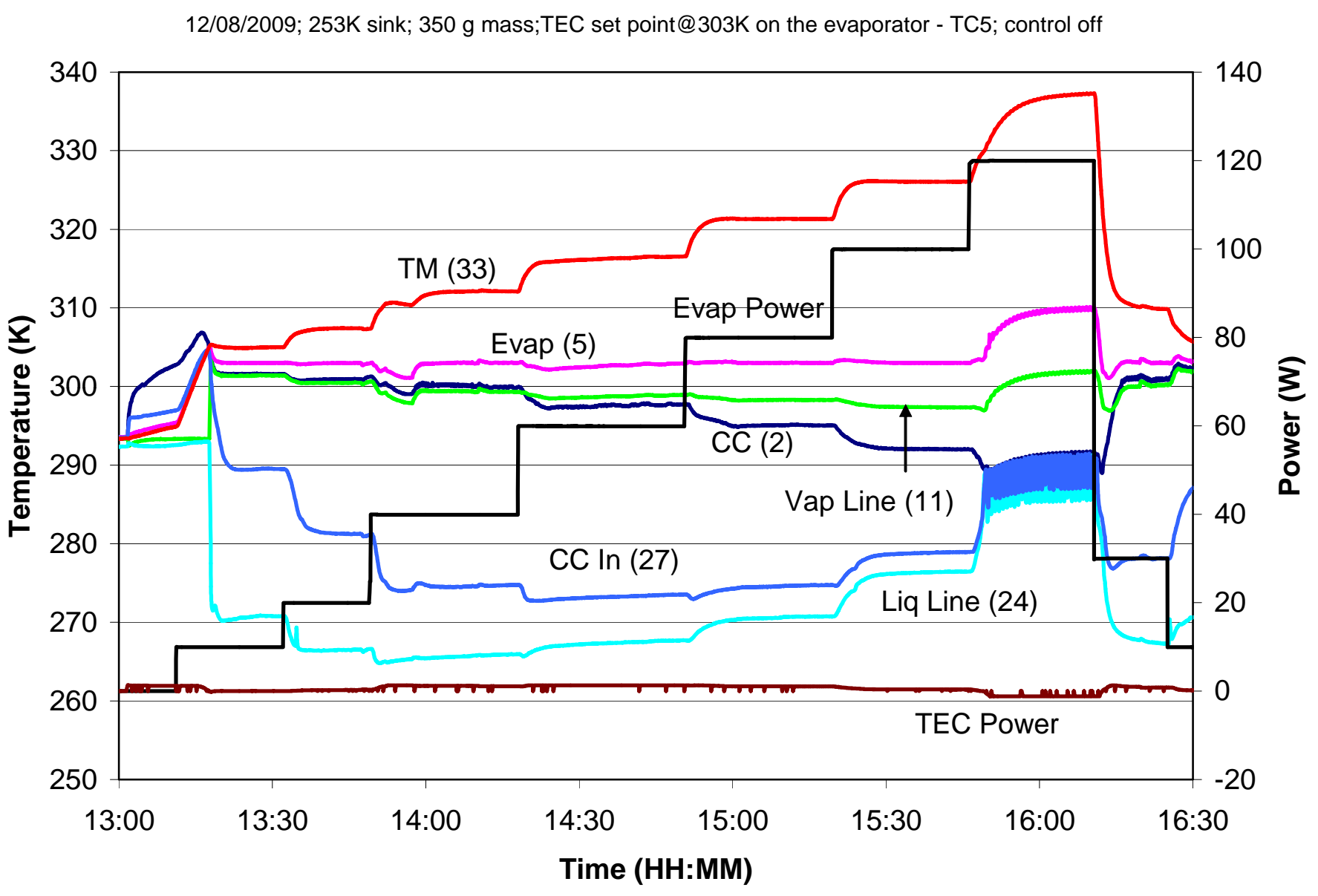




\section{TM Controlled at 313K - TEC/1W/PID/350g}

- $\quad \mathrm{TM}$ at $313 \mathrm{~K}$ between $40 \mathrm{~W}$ and $80 \mathrm{~W}$. CC and evaporator temperatures dropped at each power increase.

- At 100W condenser limit - TEC cooled CC.

- Temperature oscillations between $10 \mathrm{~W}$ and $20 \mathrm{~W}$. No oscillations at $40 \mathrm{~W}$ and above.

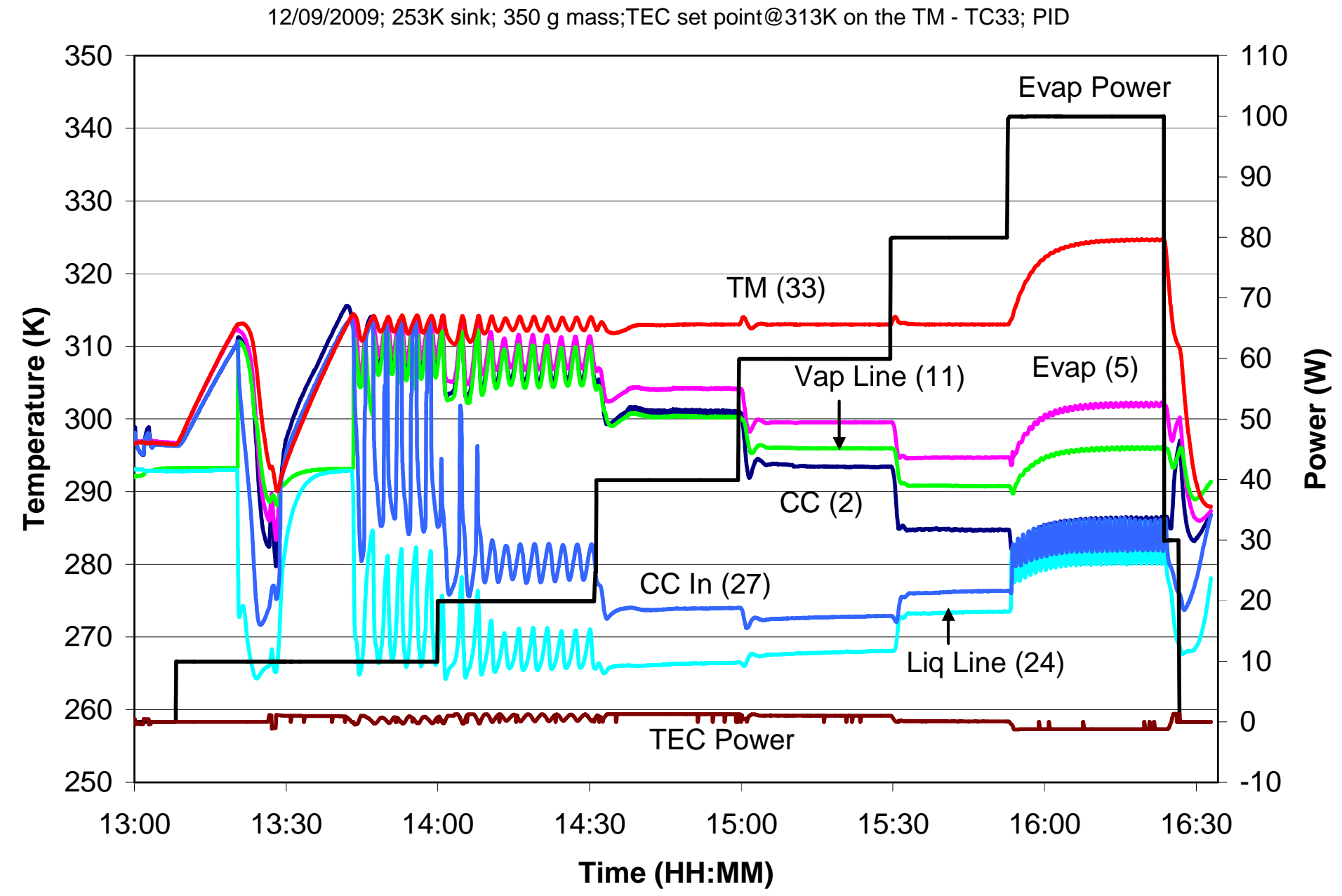




\section{TM Controlled at 313K - TEC/1W/PID/350g}

- Initially with 10W to TM, TEC was turned on to heat CC until TM reached 313K.

- When the loop started, CC temperature dropped sharply due to cold liquid injection. TEC was turned on to heat the CC. With only 10W to the TM, the loop was shut down, followed by repeated start-up/shutdown cycles.

- At 20W, temperature oscillations occurred, but no repeated start-up/shutdown cycles.

- At $40 \mathrm{~W}$, no temperature oscillations.

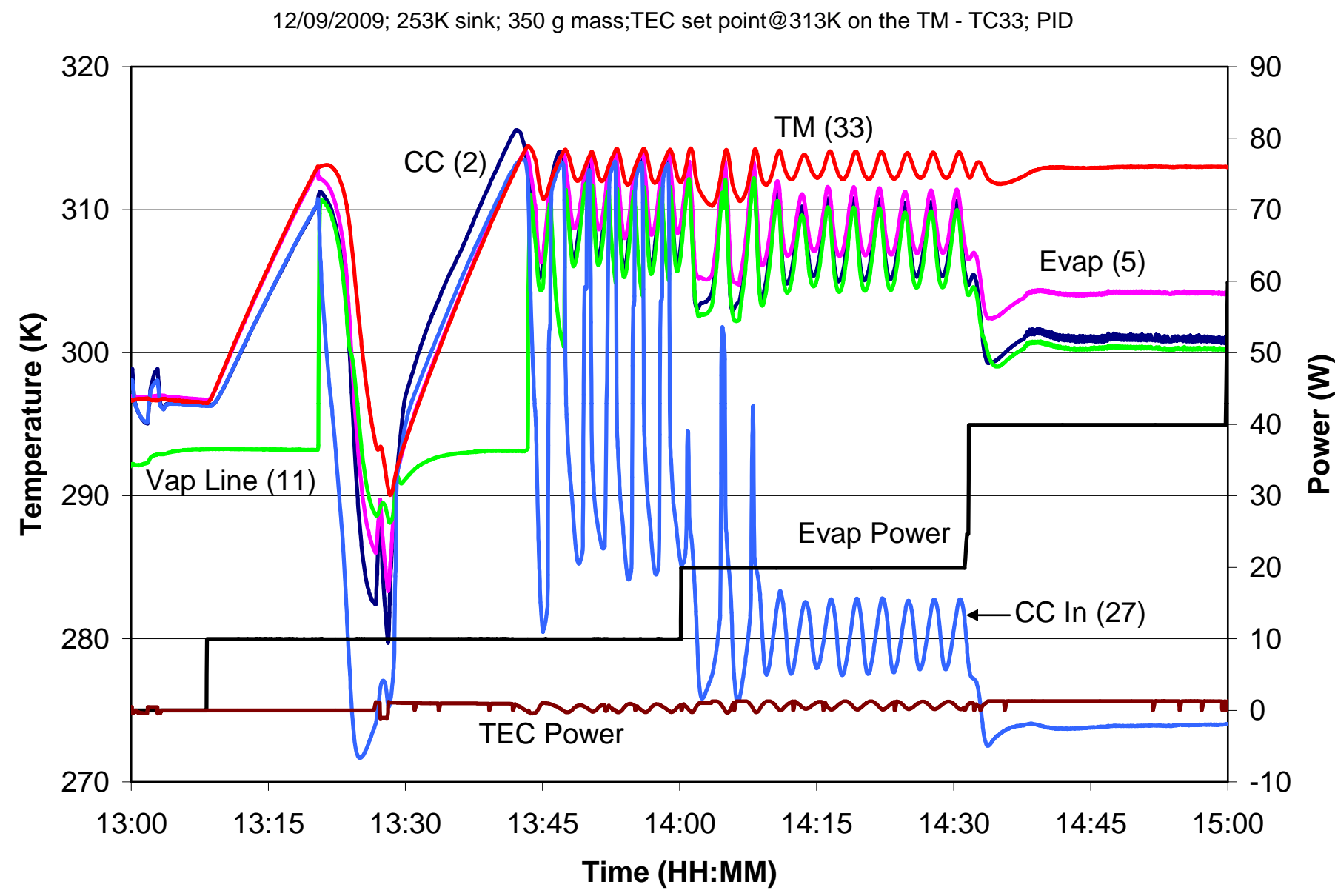




\section{Pre-heating the CC prior to Start-up}

- In typically LHP applications, the CC was preheated prior to start-up to ensure the evaporator wick is fully wetted.

- The following slides show that pre-heating the CC did not have much effect on the temperature control when the control temperature sensor was placed on the heat source.

- Using the TEC resulted in better temperature control than using the electrical heater, mainly because the TEC could also provide cooling to the CC. 


\section{TM Controlled at 313K (CC Preheated to 298K) - EH/4W/PID/350g}

At 10W, the loop repeatedly started and shut down (see next slide).

- At $40 \mathrm{~W}$, TM oscillated between $312 \mathrm{~K}$ and $314 \mathrm{~K}$, less at $60 \mathrm{~W}$. No oscillation at $80 \mathrm{~W}$.

- At $100 \mathrm{~W}$, condenser limit and CC at 287K, TM at 323K. At 120W, CC at 292K and TM at 335K.

- Temperature oscillations resumed at $30 \mathrm{~W}$ and $10 \mathrm{~W}$ (not just a start-up transient effect).

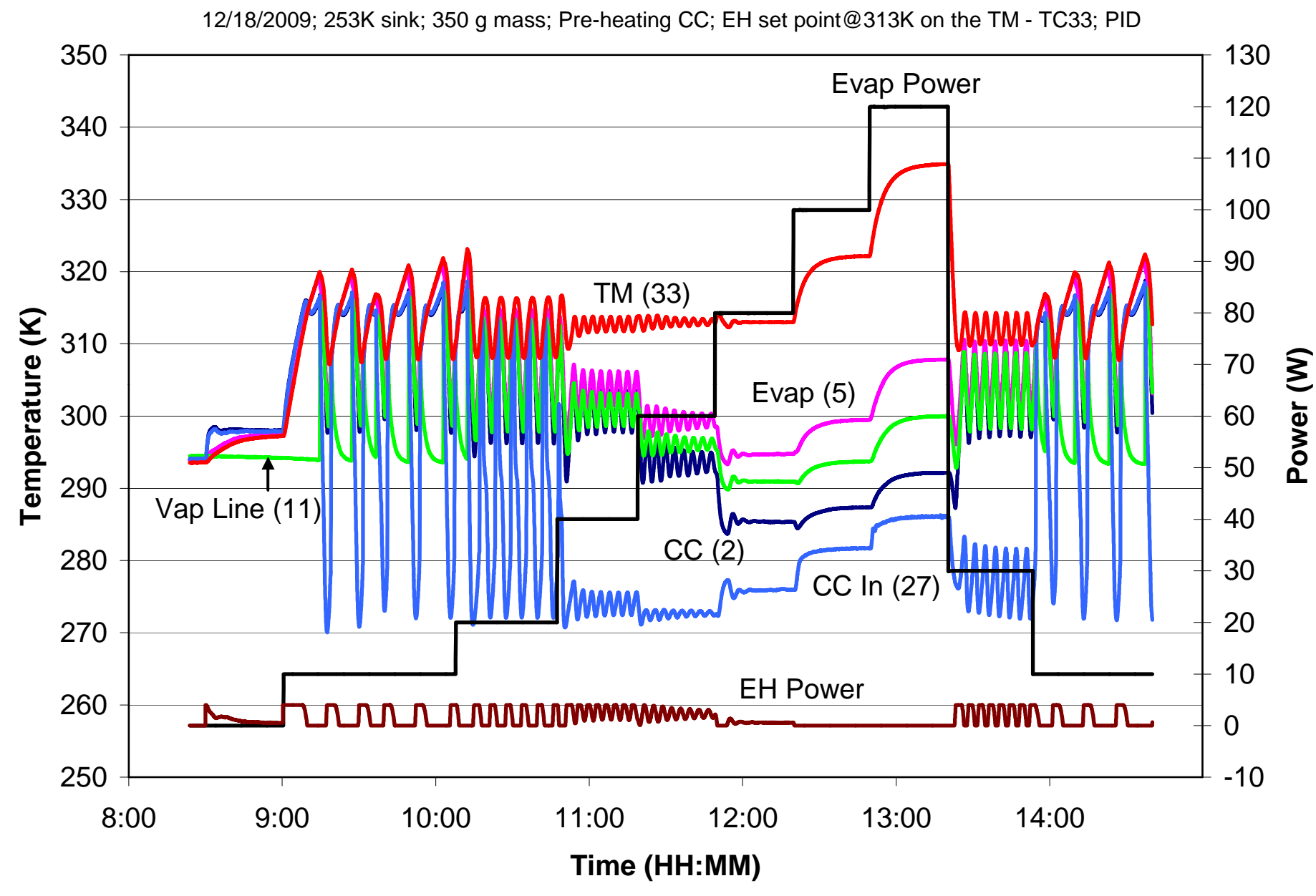




\section{TM Controlled at 313K (CC Preheated to 298K) - EH/4W/PID/350g}

- Initially, CC, evaporator, and TM were heated to 298K.

- When 10W was applied to evaporator, EH was on to heat the CC. When TM reached 313K, EH was deactivated. However, CC temperature rose due to heat leak.

- As the loop started, CC temperature dropped to 297K due to cold liquid injection. TM was at 306K.

- EH heated the CC. the loop was shut down with $4 \mathrm{~W}$ to $C C$ and 10W to TM. The loop then repeated startup and shutdown cycles.

- At 20W, the oscillation reduced. Loop did not completely shut down (TC 11 always followed TC 2) although forward/back flow alternated.

12/18/2009; 253K sink; 350 g mass; Pre-heating CC; EH set point@313K on the TM - TC33; PID

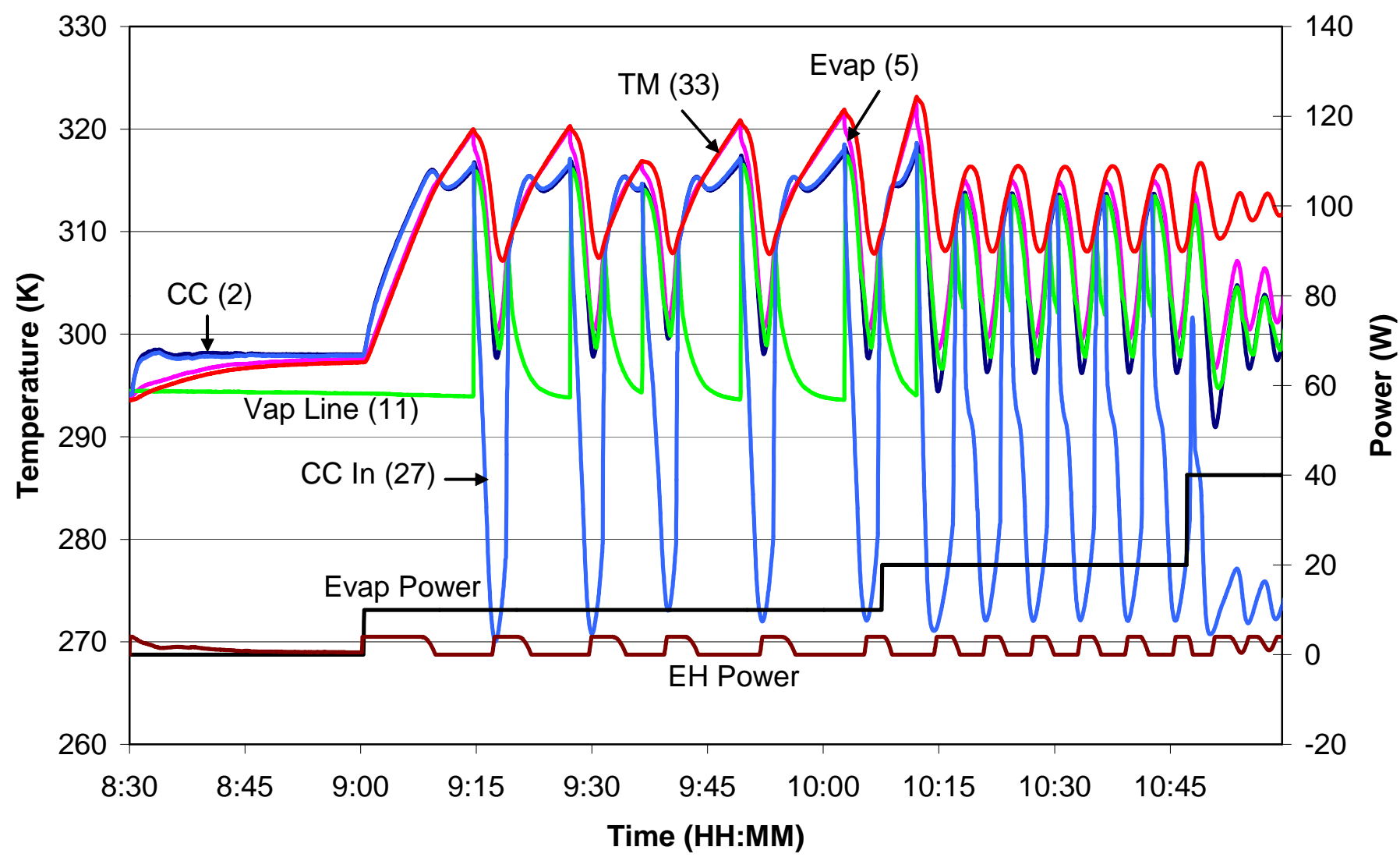




\section{TM Controlled 313K (CC pre-heated to 298K) - TEC/2W/PID/350g}

- TM controlled at $313 \mathrm{~K}$ between $10 \mathrm{~W}$ and $80 \mathrm{~W}$ - little oscillations

- At 100W - condenser limit

- TM controlled at $313 \mathrm{~K}$ again as heat load lowered to $30 \mathrm{~W}$ and $10 \mathrm{~W}$

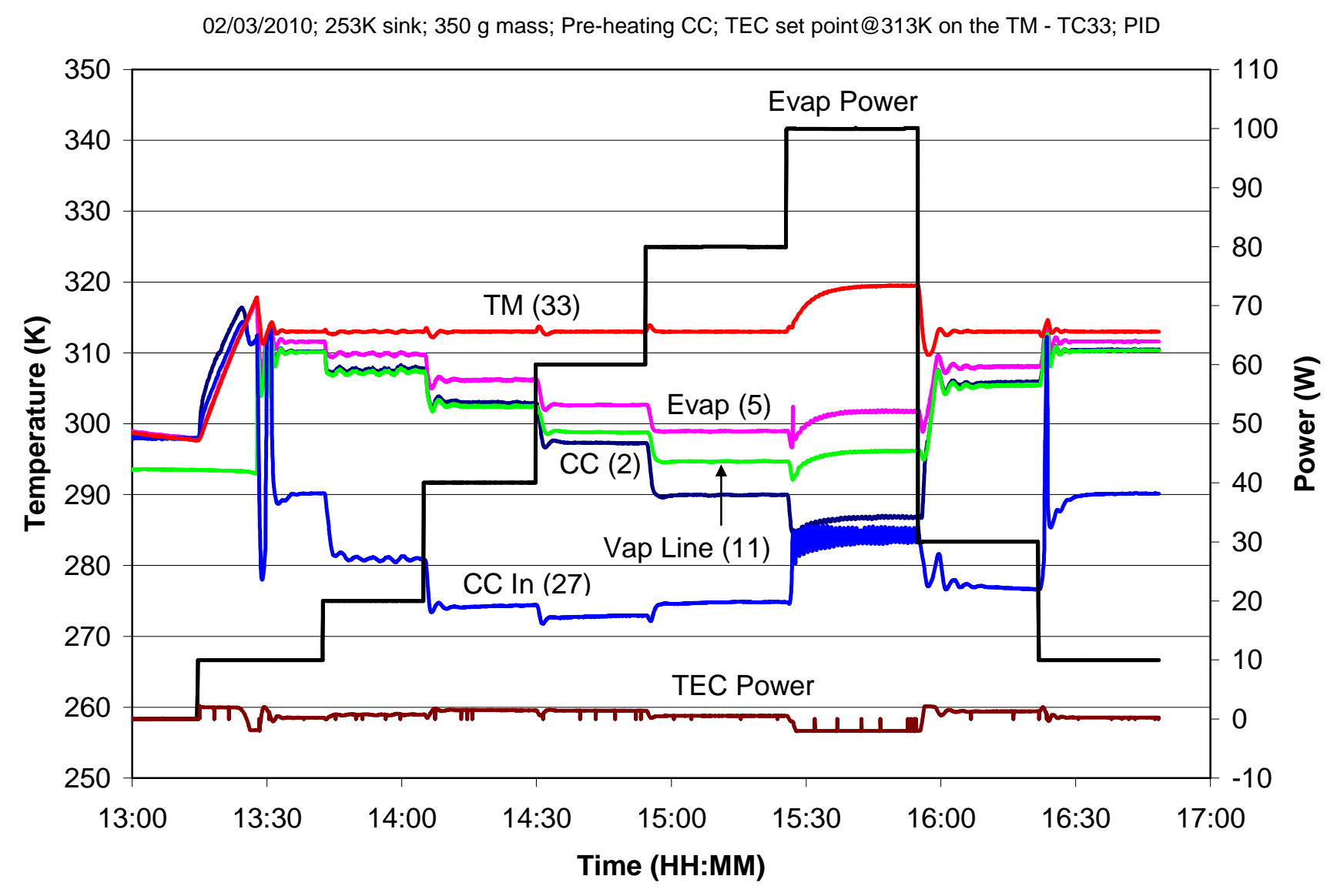




\section{TM Controlled 313K (CC pre-heated to 298K) - TEC/2W/PID/350g}

- Initially TEC heated CC so that TM would be raised to $313 \mathrm{~K}$

- When TM reached 313K, CC was at 316K. TEC cooled CC (negative power).

- $\quad$ No repeated start-up/shutdown cycles - effect of TEC power 2W vs 1W for 12/9/09

- Immediately after start-up, CC temperature dropped due to cold liquid injection, bringing the TM to 312K.

- In the next heating cycle, the loop was shut down and re-started. The cold shock was mild and the loop soon reached SS.

02/03/2010; 253K sink; 350 g mass; Pre-heating CC; TEC set point@313K on the TM - TC33; PID

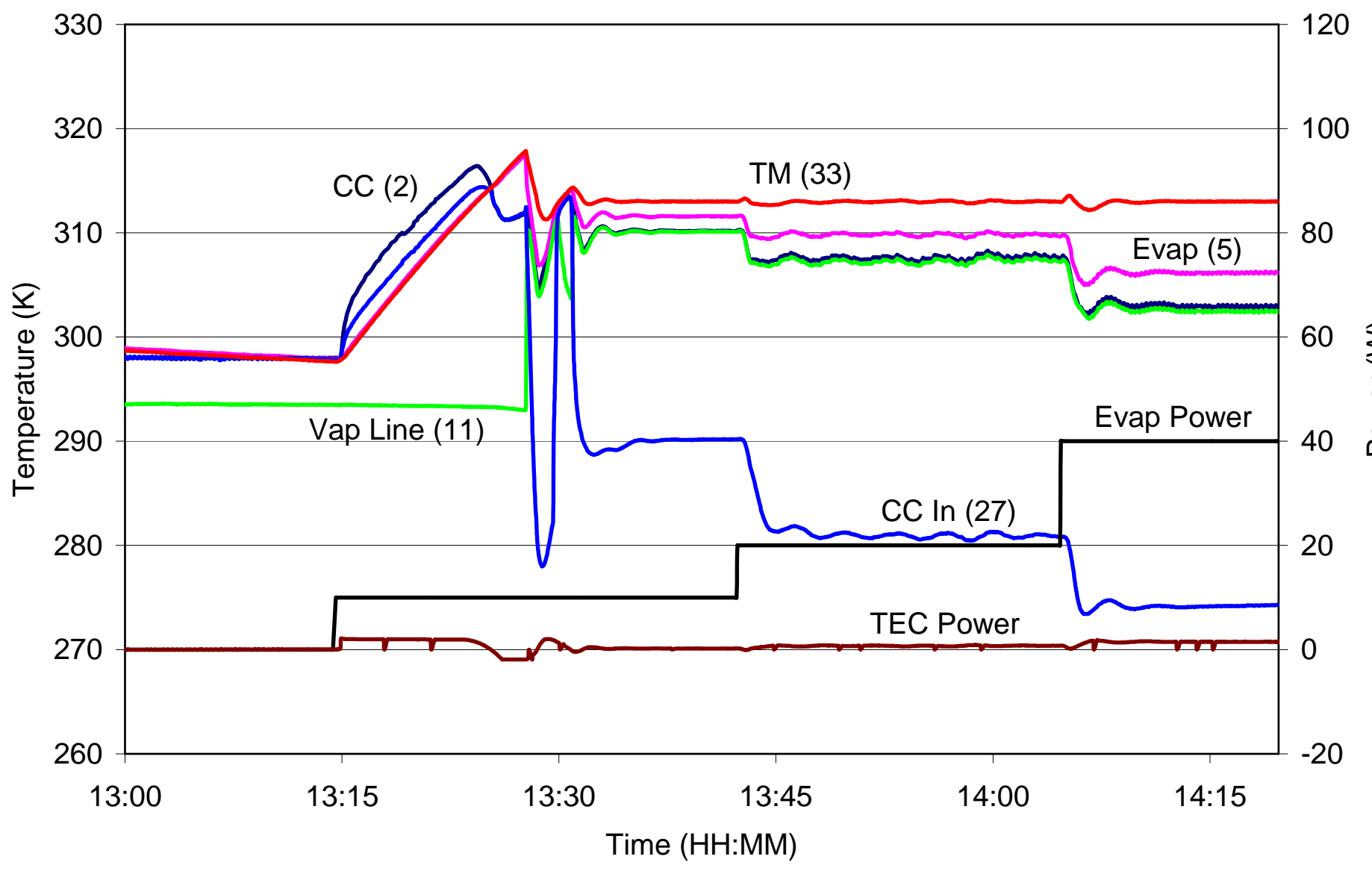




\section{Pre-set CC Temperature Profile to Control TM at 313K (CC Preheated to 298K) - EH/4W/PID/350 g}

- The CC temperature was pre-set to previously experimentally determined values (function of power input) in order to keep TM at 313K at all powers.

- The control temperature sensor was located on the CC.

- Temperature oscillations at $10 \mathrm{~W}$ and $20 \mathrm{~W}$, stable $40 \mathrm{~W}$ to $100 \mathrm{~W}$

- Condenser limit was reached at 100W; EH deactivated, and TM at 317K.

02/04/2010; 253K sink; 350 g mass; Pre-heating CC; EH - adjustable CC temp. to control TM@313K; PID

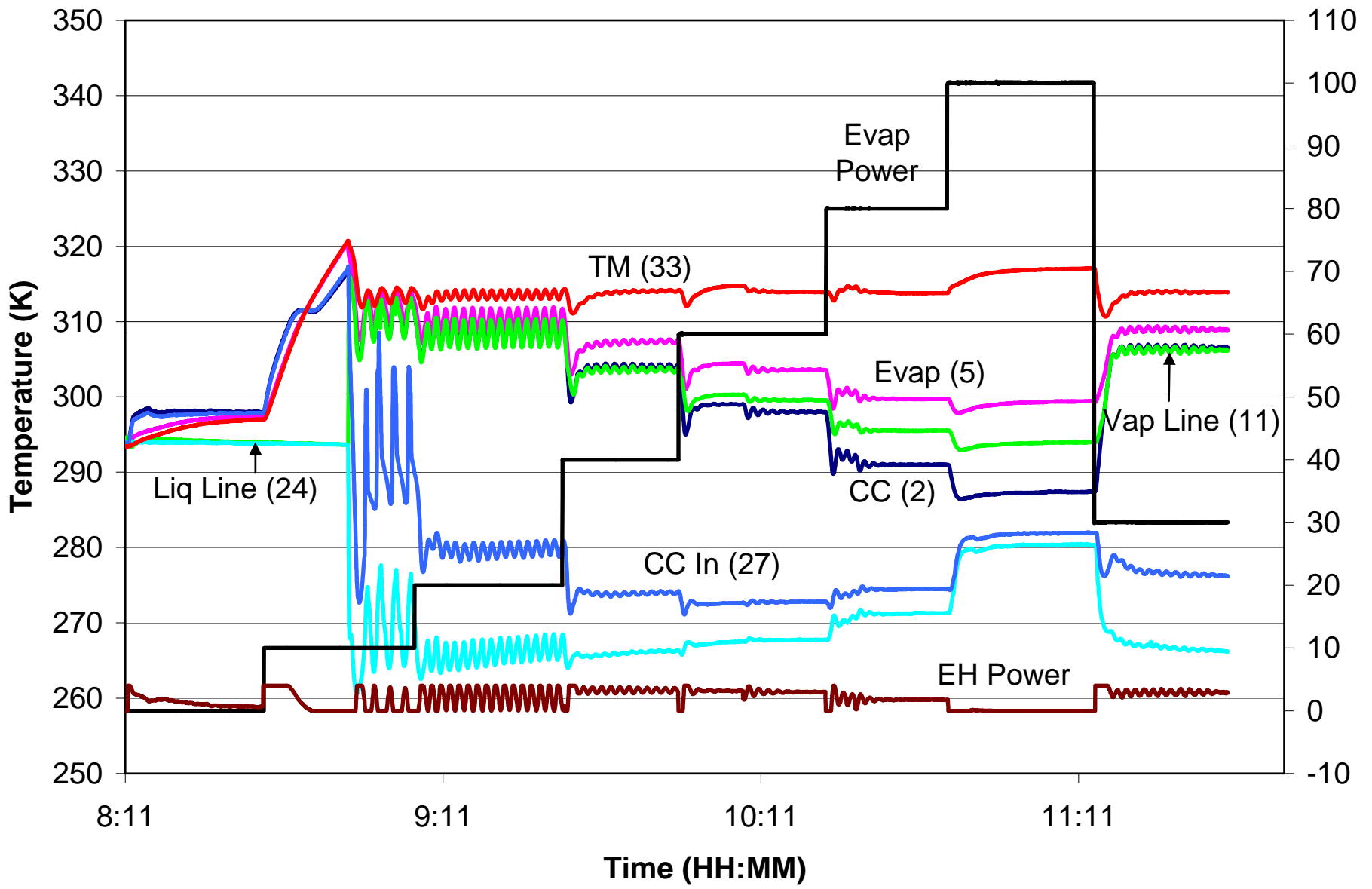


- The CC temperature was pre-set to previously experimentally determined values (function of power input) in order to keep TM at 313K at all powers.

- The control temperature sensor was located on the CC.

- All temperatures were stable. At each power increase, TM temperature dropped because of a step change in the pre-determined CC set point.

- Condenser limit was reached at 100W. CC could not cooled further to maintain the TM at 313K.

02/04/2010; 253K sink; 350 g mass; Pre-heating CC; TEC - adjustable CC temp. to control TM@313K; PID

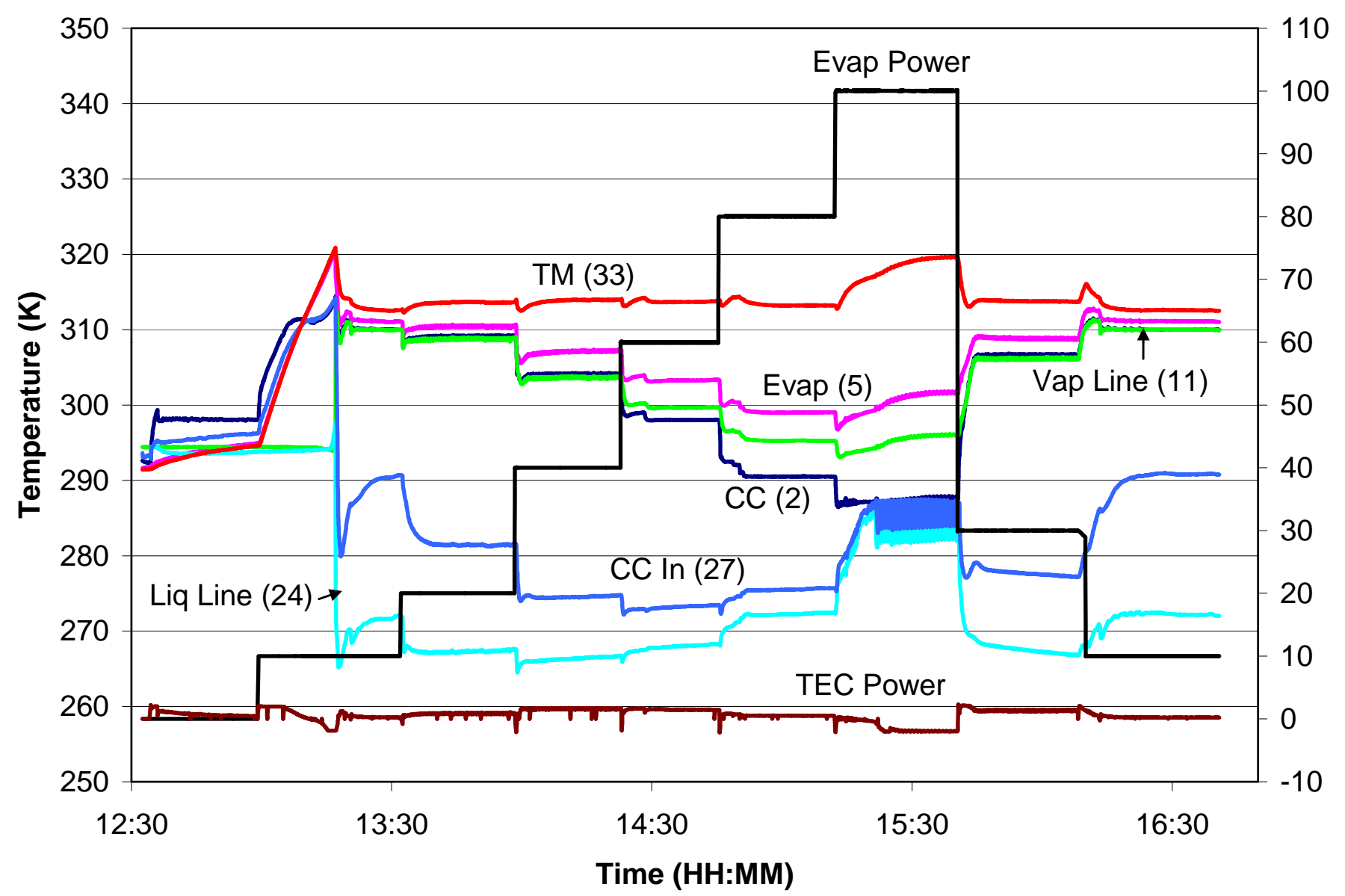




\section{Effect of Thermal Mass}

- The following slides show the test result with $110 \mathrm{~g}$ thermal mass attached to the evaporator.

- In theory, a smaller thermal mass should reduce the time delay in the feedback control when the control temperature sensor is located on the thermal mass.

- Test results under the current test program did not show much thermal mass effect on the LHP temperature control. This may be due to the proximity of the control temperature sensor and the heater locations on the thermal masses.
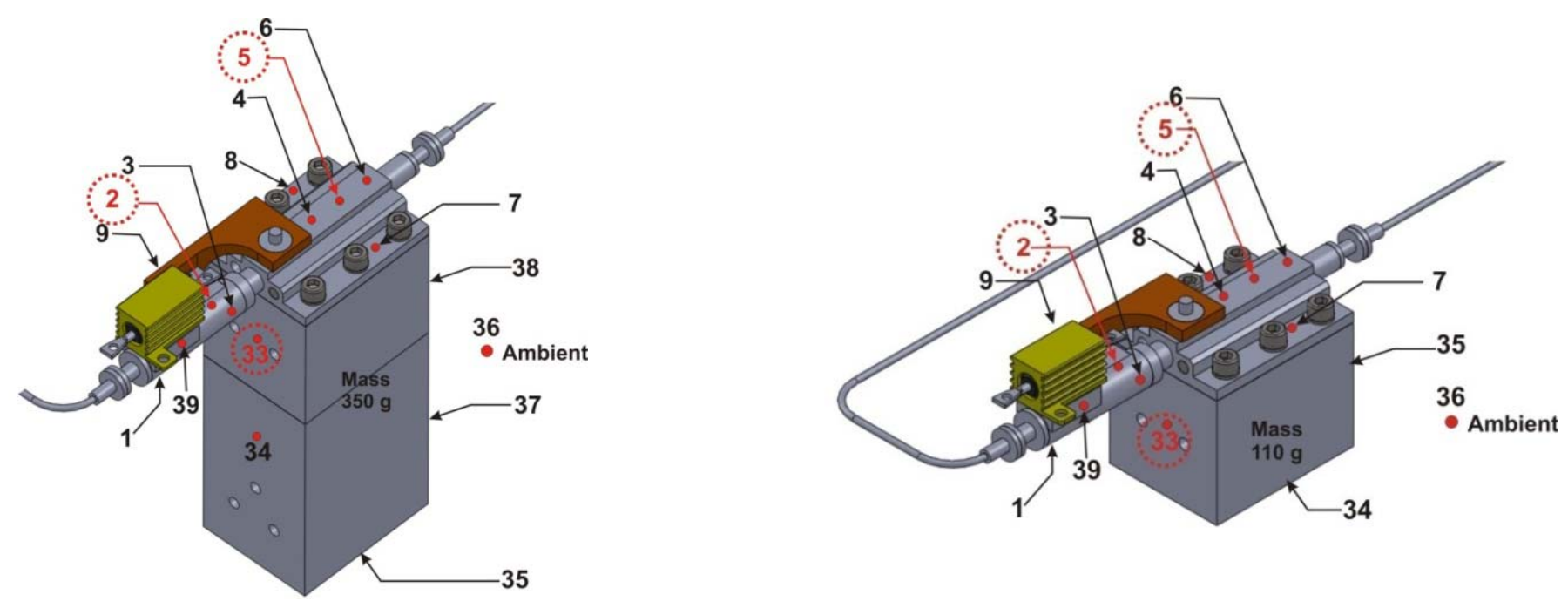


\section{TM Maintained at 313K (CC Preheated to 298K) - EH/4W/PID/110g}

- TM temp was maintained at 313K with oscillations up to $80 \mathrm{~W}$.

- At 100W, TM temp at 315K due to condenser limit (EH deactivated, no oscillations).

- Temp oscillations resumed at $30 \mathrm{~W}$ and $10 \mathrm{~W}$.

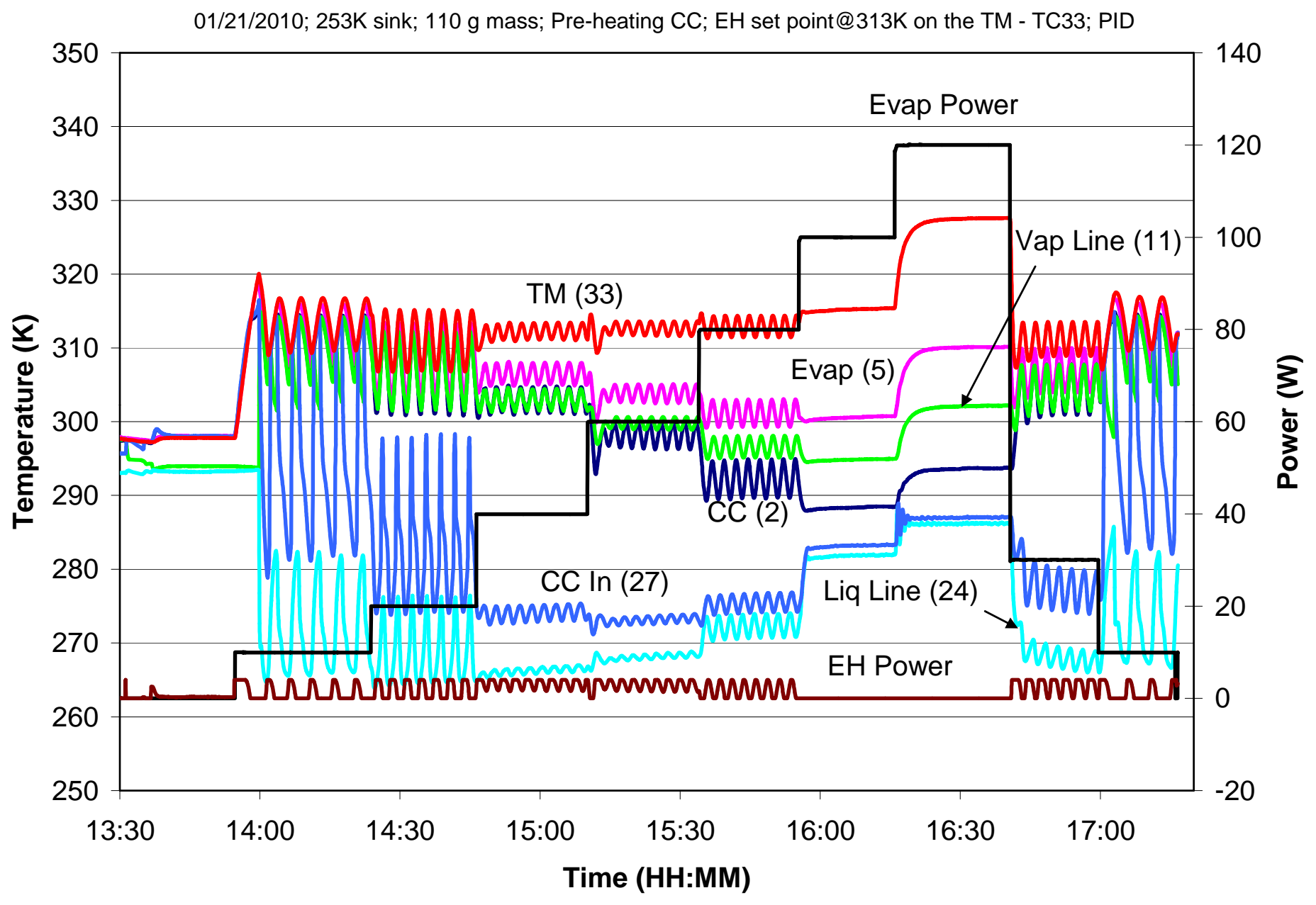




\section{TM Maintained at 313K (CC Preheated to 298K) - EH/4W/PID/110g}

- At 10W, repeated start-up/shutdown cycles even with $110 \mathrm{~g}$ TM.

- At 20W, still large temperature oscillations.

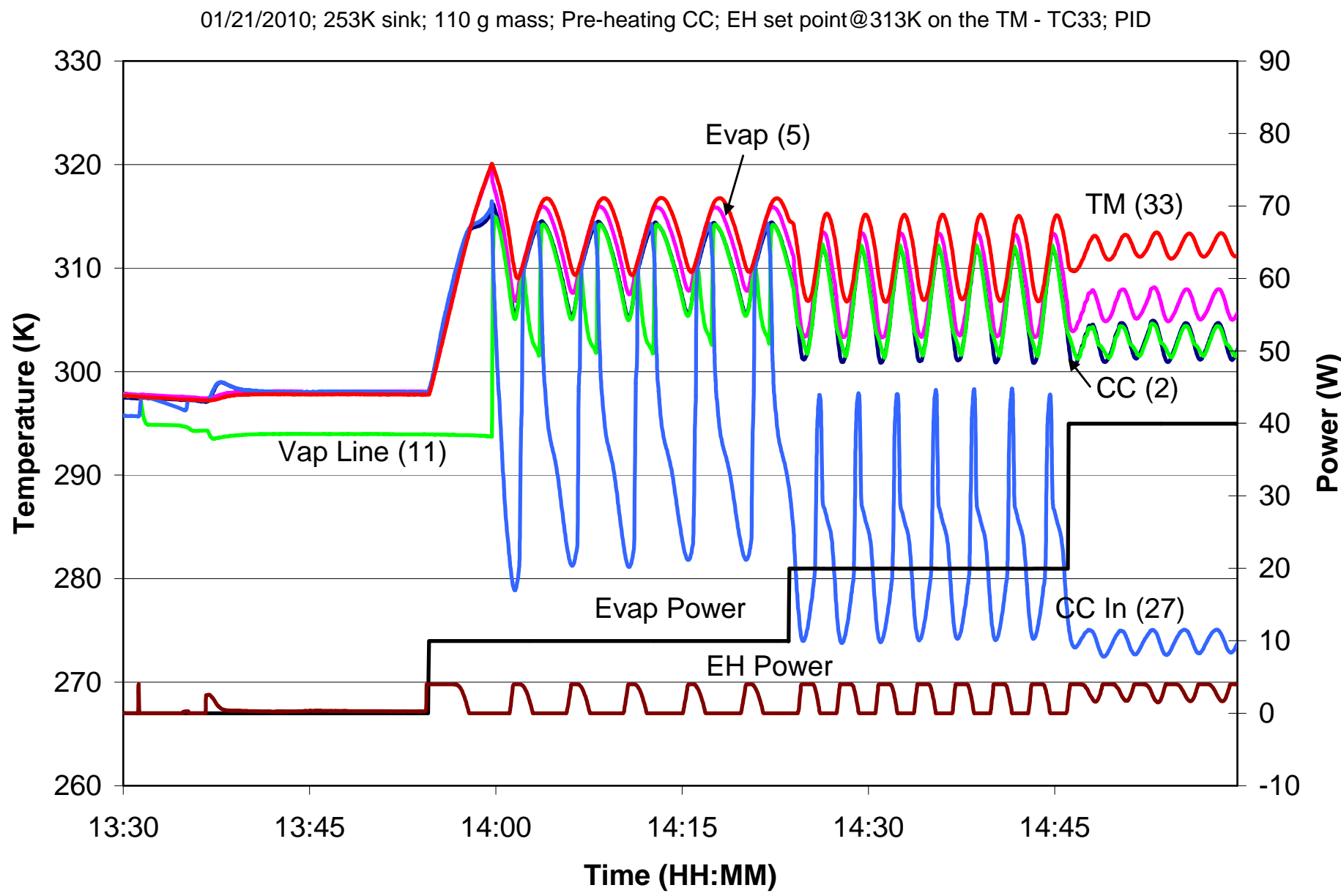




\section{TM Controlled at 313K (CC Pre-Heated to 298K) - TEC/2W/PID/110g}

- TM was controlled at $313 \mathrm{~K}$ between $20 \mathrm{~W}$ and $80 \mathrm{~W}$

- Condenser limit was reached at 100W; TM at 323K

- TM was controlled at $313 \mathrm{~K}$ as heat load decreased to $30 \mathrm{~W}$

- Temperature oscillations at $10 \mathrm{~W}$ at the beginning and the end of the test.

01/20/2010; 253K sink; 110 g mass; Pre-heating CC; TEC set point@313K on the TM - TC33; PID

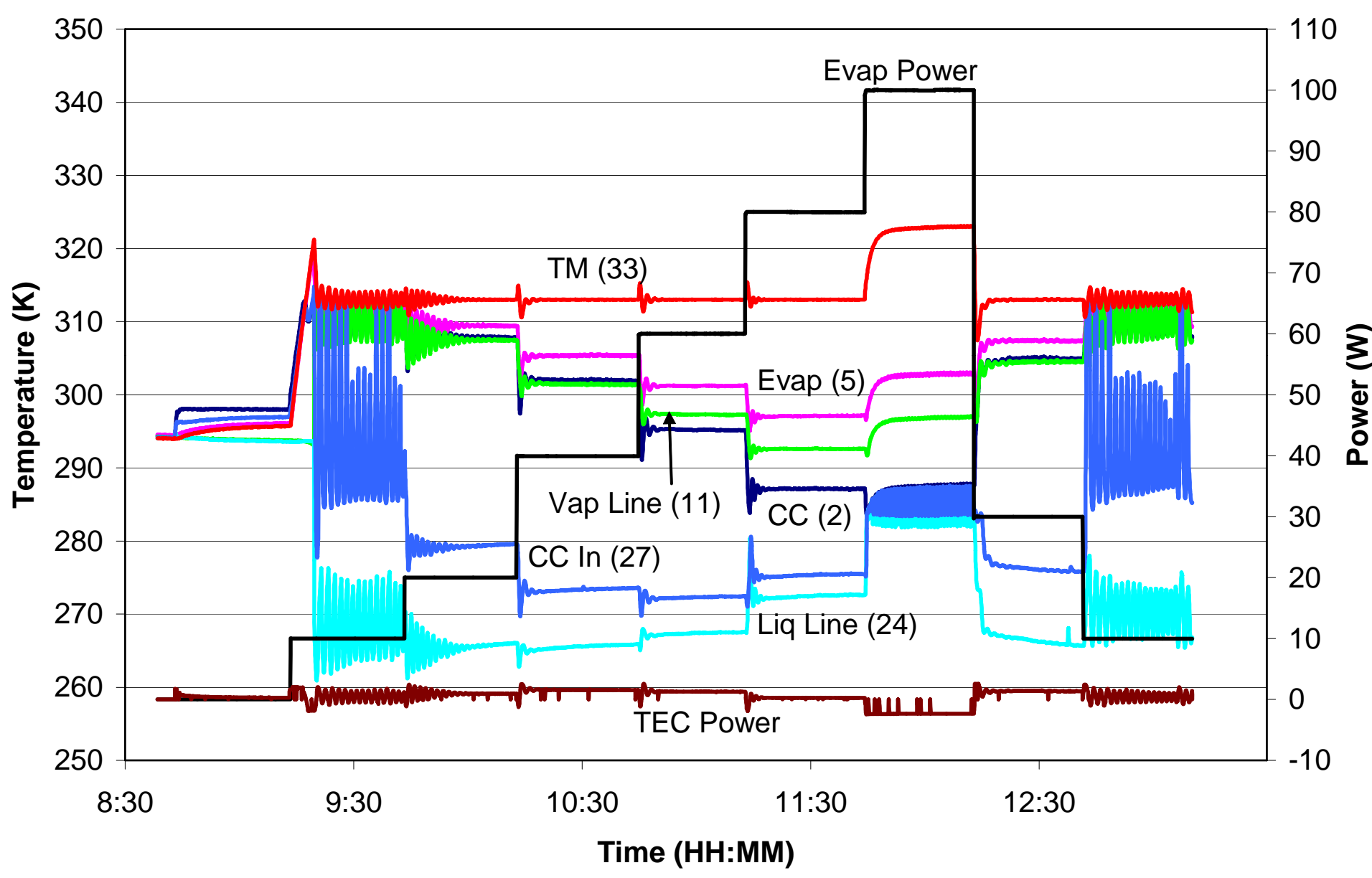




\section{TM Controlled at 313K (CC Pre-Heated to 298K) - TEC/2W/PID/110g}

- TEC $2 \mathrm{~W}$ max. CC temperature rose faster than that of TM

- $\quad$ TEC cooled CC after TM reached 313K, the loop then started. TM oscillated between $312.3 \mathrm{~K}$ and $313.7 \mathrm{~K}$

- Repeated start-up/shutdown at $10 \mathrm{~W}$

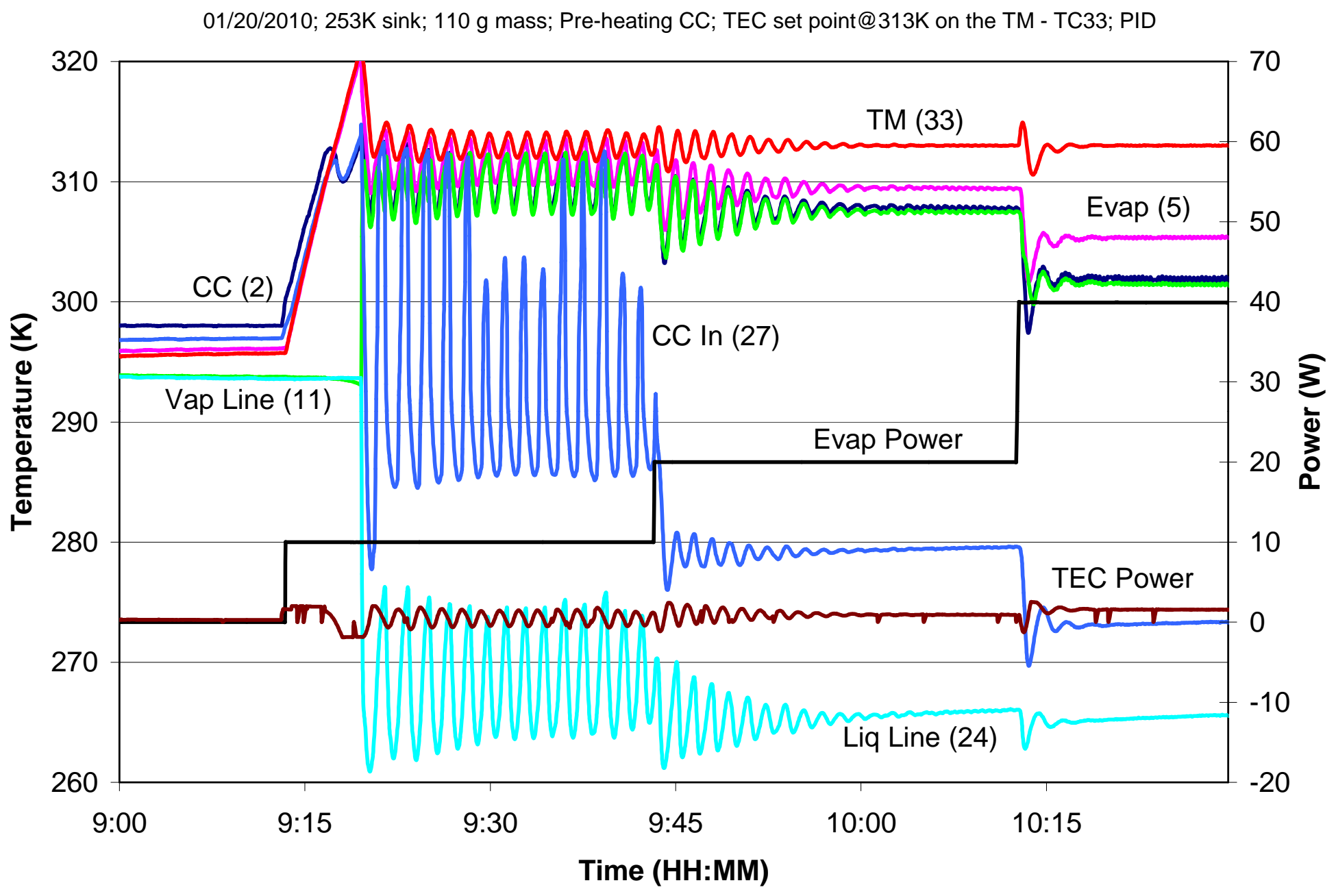




\section{Using Pre-set CC Set Point to Maintain TM at 313K (CC Pre- Heated to 298K) - EH/4W/PID/110g}

- The CC temperature was pre-set to previously experimentally determined values (function of power input) in order to keep TM at 313K at all powers.

- $\quad$ The control temperature sensor was located on the CC.

- TM temperature was controlled at 313K between $10 \mathrm{~W}$ and $80 \mathrm{~W}$. Condenser limit was reached at $100 \mathrm{~W}$.

- At each CC set point change, TM could not follow immediately, resulting in TM temperature fluctuations.

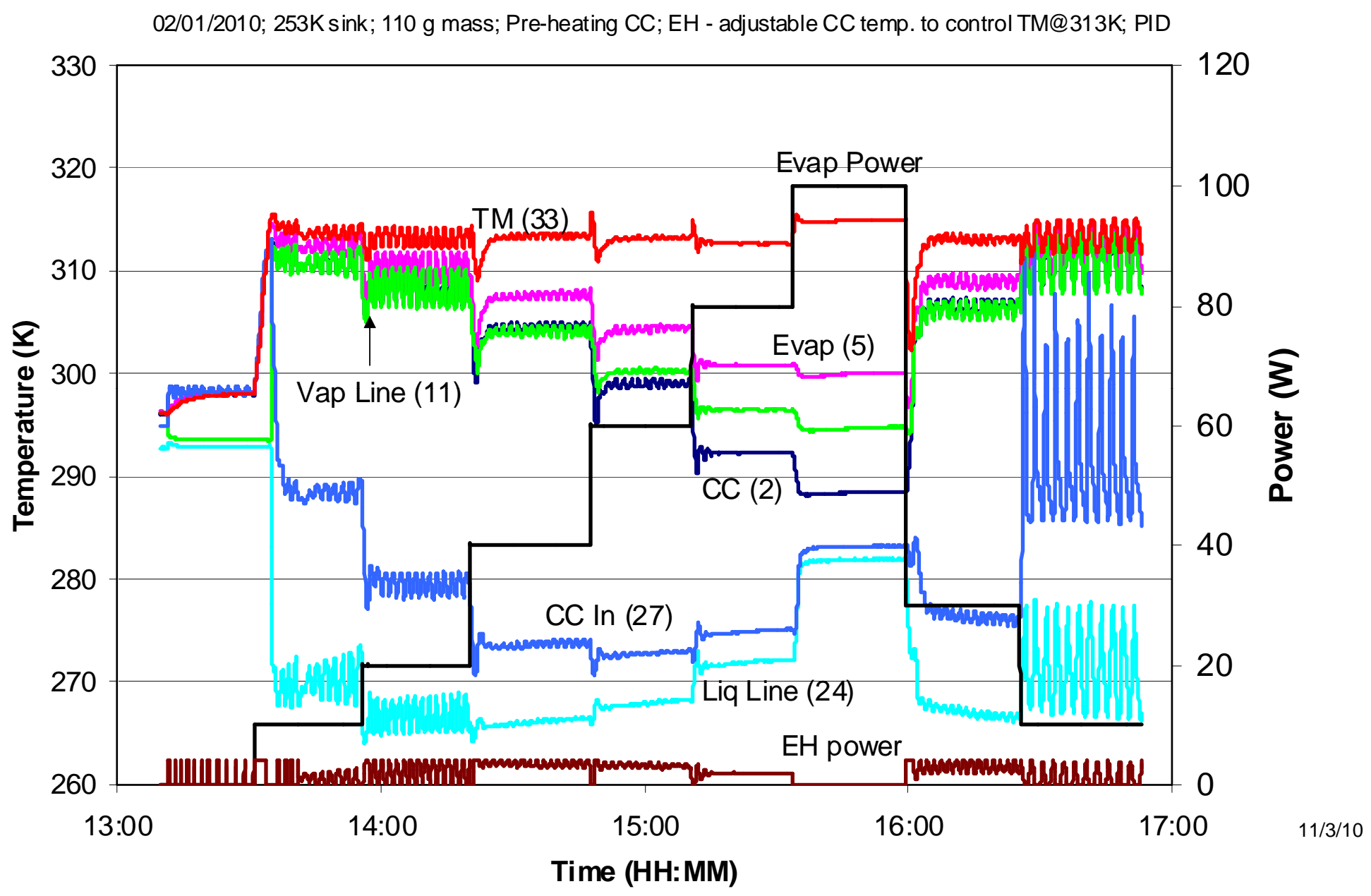




\section{Using Pre-set CC Set Point to Maintain TM at 313K (CC Pre- Heated to 298K) - TEC/2W/PID/110g}

- The CC temperature was pre-set to previously experimentally determined values (function of power input) in order to keep TM at 313K at all powers.

- The temperature sensor was located on the CC.

- TM temperature was controlled at 313K between $10 \mathrm{~W}$ and $80 \mathrm{~W}$. Condenser limit was reached at $100 \mathrm{~W}$.

- TM temperature oscillated at $10 \mathrm{~W}$ and $20 \mathrm{~W}$.

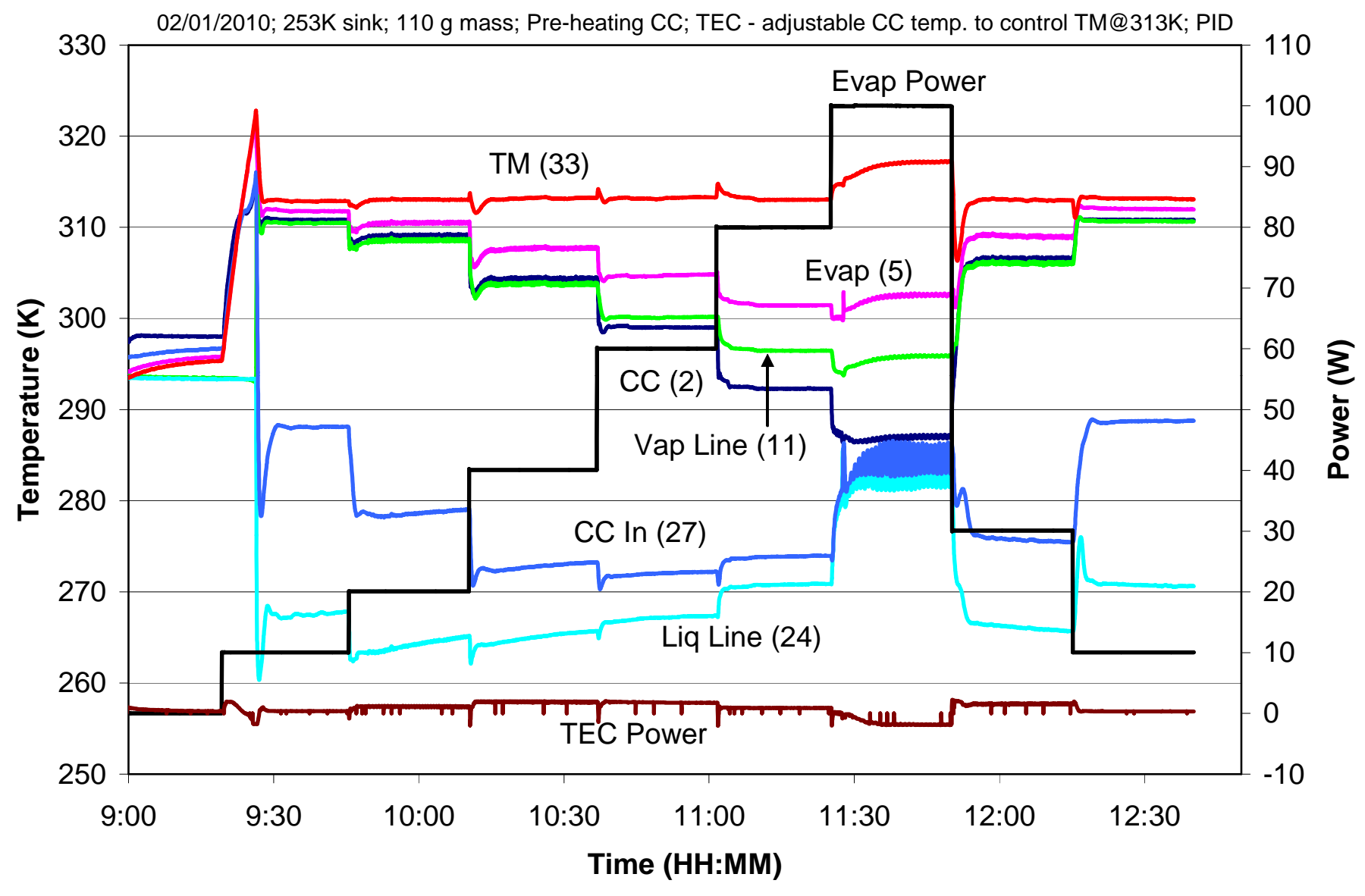




\section{Summary of Test Results}

- The LHP CC temperature or the heat source temperature can be used for LHP set point control with a control heater attached to the CC.

- The traditional method of using CC temperature for LHP set point control yields best temperature stability.

- However, the heat source temperature will vary with the heat output from the heat source.

- Using the heat source temperature as feedback for LHP set point control will maintain the heat source at the desired temperature regardless of the heat output.

- However, temperature oscillations may appear during transients and can be severe at low heat loads.

- Using a TEC to control the CC temperature yields better temperature stability than using an electric heater.

- The control heater power also affects the temperature stability. 


\section{Concluding Remarks}

- There are many factors to be considered in deciding which temperature should be used for LHP feedback control.

- For most applications, using the CC temperature for feedback control is preferred as long as the heat source can be maintained within the required temperature range.

- A simple control algorithm will suffice for SS and transients.

- The CC set point can be varied while the LHP is operating in space.

- The heat source temperature can best be used for feedback control for applications where the heat load varies constantly without frequent LHP start-ups and shut-downs.

- The heat source can be maintained within a tight temperature range through automatic adjustments of the $\mathrm{CC}$ temperature.

- More sophisticated (smart) control algorithms must be employed when frequent start-ups or rapid power changes are involved if the heat source temperature is to be used for feedback control. 


\section{QUESTIONS?}

